Divergence amid recurring gene flow

\title{
Divergence amid recurring gene flow: complex demographic processes during speciation are the growing expectation for forest trees
}

\section{Constance E. Bolte ${ }^{1,4}$, Trevor M. Faske ${ }^{2}$, Christopher J. Friedline ${ }^{3}$, and Andrew J. Eckert $^{3}$}

${ }^{1}$ Integrative Life Sciences Doctoral Program, Virginia Commonwealth University, Richmond, VA, USA

9 2Ecology, Evolution \& Conservation Biology Doctoral Program, University of Nevada, 10 Reno, NV, USA

11 32Department of Biology, Virginia Commonwealth University, Richmond, VA, USA

$12 \quad{ }^{4}$ Corresponding author; boltece@vcu.edu

\section{Abstract}

15 Long-lived species of trees, especially conifers, often display weak patterns of reproductive isolation, but clear patterns of local adaptation and phenotypic divergence.

17 Discovering the evolutionary history of these patterns is paramount to a generalized understanding of speciation for long-lived plants. We focus on two closely related yet phenotypically divergent pine species, Pinus pungens and $P$. rigida, that co-exist along

20 high elevation ridgelines of the southern Appalachian Mountains. Based on genome-wide

21 RADseq data, patterns of population structure for each species were uncorrelated to

22 geography and the environment. Signals of admixture, however, were present range-

23 wide. When combined with information from contemporary and historical species

24 distribution models, these patterns are consistent with a complex evolutionary history of

25 speciation. This was confirmed using inferences based on the multidimensional site-

26 frequency spectrum, where demographic modeling inferred recurring gene flow since

27 divergence (9.3 - 15.4 million years ago) and population size reductions that align in

28 timing with the last interglacial period ( 120 - 140 thousand years ago). This suggests

29 that phenotypic and genomic divergence, including the evolution of divergent

30 phenological schedules leading to partial reproductive isolation, as previously 
Divergence amid recurring gene flow

31 documented for these two species, can happen rapidly, even between long-lived species

32 of pines.

34 Keywords: conifer speciation, Pinus pungens, Pinus rigida, reproductive isolation, 35 population genetics, species distributions

\section{Statements and Declarations}

38 The authors have no financial or proprietary interests in any material discussed in this

39 article. Field sampling permits at National Parks and State Parks were obtained prior to

40 collecting leaf tissue: ACAD-2017-SCI-007, BLRI-2013-SCI-0027, GRSM-2017-SCI-

41 2028, ZZ-RCP-112514, and SFRA-1725.

\section{Acknowledgements}

44 This research was funded by Virginia Commonwealth University (VCU) Department of

45 Biology, VCU Integrative Life Sciences, and National Science Foundation (NSF) awards

46 to Andrew J. Eckert (NSF-EF-1442486) and Christopher J. Friedline (NSF-NPGI-PRFB-

47 1306622). We thank Mitra Menon and Rebecca Piri for their assistance with field 48 sampling, Brandon Lind for providing computational support, and the undergraduate

49 researchers who helped with the DNA extraction protocol: Kaylyn Carver, Casey Harless,

50 and Leslie Ranson. Demographic inference requires large computational resources, and

51 we thank the VCU Center for High Performance Computing for proving those. 
Divergence amid recurring gene flow

\section{Introduction}

56 The process of speciation has been characterized as a continuum of divergence

57 underpinned with the expectation that reproductive isolation strengthens over time

58 leading to increased genomic conflict between species (Seehausen et al. 2014). While

59 the term continuum suggests linear directionality, it is better thought of as a multivariate

60 trajectory that is nontemporal, allowing stalls and even breakdown of reproductive barriers

61 in the overall progression toward complete reproductive isolation (Cannon and Petit 2020;

62 Kulmuni et al. 2020). Indeed, speciation can occur with or without ongoing gene flow and

63 demographic processes such as expansions, contractions, isolation, and introgression

64 leave detectable genetic patterns within and among populations of species that affect the

65 evolution of reproductive isolation (Nosil 2012; e.g., Gao et al. 2012). Divergence histories

66 with gene flow are an emerging pattern for species of forest trees with reproductive

67 isolation often developing through prezygotic isolating mechanisms and reinforced by

68 environmental adaptation (Abbott 2017; Cavender-Bares 2019). Together, these two

69 processes can facilitate the development of genomic incompatibilities over time (Baack

70 et al. 2015).

72 Climate and geography are well-established drivers of demographic processes and

73 patterns (Hewitt 2001). For the past 2.6 million years, Quaternary climate has oscillated

74 between glacial and interglacial periods causing changes in species distributions, but the

75 significance of these changes and their influence on population differentiation has varied

76 by region and taxa (Hewitt 2004; Lascoux et al. 2004). In North America, the effects of 
Divergence amid recurring gene flow

77 Quaternary climate on tree species distributions and patterns of genetic diversity have

78 been profound but more drastic for species native to northern (i.e., previously glaciated)

79 and eastern regions. For instance, the geographical distribution of white oak (Quercus

80 alba L.), a native tree species to eastern North America, experienced greater shifts since

81 the last interglacial period, approximately 120 thousand years ago (kya), compared to the

82 distributional shifts of valley oak (Quercus lobata Née) in California (Gugger et al. 2013).

83 For the latter, distributional, and hence niche, stability was correlated with higher levels

84 of genetic diversity.

86 Given the climate instability of eastern North America since the last interglacial period

87 (LIG; 120 kya), a host of phylogeographic studies have reported genetic diversity

88 estimates for taxa of this region and the genetic structuring of populations due to

89 geographic barriers such as the Appalachian Mountains and Mississippi River (Soltis et

90 al. 2006) as well as postglacial expansion (e.g., Gougherty et al. 2020). The vast majority

91 of tree taxa in these studies, however, were angiosperms, with the divergence history of

92 only one closely related pair of conifer species native to this region, Picea mariana (Mill.)

93 Britton, Sterns, \& Poggenb. and P. rubens Sarg., being fully characterized (Perron et al.

94 2000; Lafontaine et al. 2015). The relative differences in geographical distributions and

95 genetic diversities across $P$. mariana and $P$. rubens, as well as models of demographic

96 inference, suggest a progenitor-derivative species relationship that initiated

97 approximately 110 kya through population contractions and geographical isolation.

98 Despite this history, these two species actively hybridize today. In general, speciation

99 among conifer lineages remains an enigmatic process (Bolte and Eckert 2020), largely 
Divergence amid recurring gene flow

100 because there is a mismatch between species-level taxonomy and the existence of

101 reproductive isolation, so that hybridization among species is common both naturally as

102 well as artificially (Critchfield 1986). The ability to hybridize, moreover, is idiosyncratic,

103 with examples ranging from well-developed incompatibilities among populations within

104 species (e.g., P. muricata D. Don; Critchfield 1967) to the almost complete lack of

105 incompatibilities among diverged and geographically distant species ( $P$. wallichiana A. B.

106 Jacks. from central Asia and P. monticola Douglas ex D. Don from western North

107 America; Wright 1959). Thus, the tempo and mode for the evolution of reproductive

108 isolation for conifers remains largely unexplained despite decades of research into

109 patterns of natural hybridization, crossing rates, and the mechanisms behind documented

110 incompatibilities (McWilliam 1959; Kriebel 1972; Hagman 1975; Critchfield 1986;

111 Vasilyeva and Goroshkevich 2018).

112

113 The key to understanding the evolution of reproductive isolation, and hence a more

114 developed explanation of the process of speciation for conifers, is the role of demography

115 and gene flow during the divergence among lineages. Analytical approaches have been

116 developed to infer past demographic processes from population genomic data, which can

117 now easily be generated even for conifers (Parchman et al. 2018). While many studies

118 have used demographic inference methods to describe the phylogeographic history of a

119 single species (e.g., Gugger et al. 2013; Li et al. 2013; Bagley et al. 2020; Ju et al. 2019;

120 Park and Donoghue 2019; Capblancq et al. 2020; Yang et al. 2020; Labiszak et al. 2021),

121 some of these established methods have also be used to infer divergence histories

122 between two or three species (e.g., Zou et al. 2013; Christe et al. 2017; Kim et al. 2018; 
Divergence amid recurring gene flow

123 Menon et al. 2018). Single species inferences have found that the last glacial maximum

124 (LGM; 22,000 years ago) affected distributional shifts and intraspecific gene flow

125 dynamics, while multispecies studies have focused almost solely on how these climatic

126 oscillations drove periods of increased and decreased interspecific gene flow which

127 contributed to the formation of environmentally dependent hybrid zones, ancient

128 periodical introgression, or adaptive divergence in the development of reproductive 129 isolation.

131 The number of potential divergence histories underlying even a modest number of

132 species is vast. The preemptive formation of a hypothesis from historical species 133 distribution modeling (SDM), however, can aid in defining a more realistic set of models 134 from which to make inference, as well as to examine the impact of the climate change on 135 genetic diversity and demographic processes (Carstens and Richards, 2007). For 136 example, Lima et al. (2017) modeled distributional changes for Eugenia dysenterica DC.

137 between the LGM and today which led to a hypothesis that range stability was more likely 138 than range expansion or contraction in this South American region. Their SDM informed 139 hypothesis was supported by range-wide, E. dysenterica genetic data. Likewise, SDMs 140 across several time points allows for estimation of habitat suitability change (i.e., a proxy 141 for contraction or expansion) and distributional overlap of multiple species (i.e., potential 142 gene flow). With these quantified changes, testable hypotheses emerge, lending to more 143 deliberate investigations of speciation through justified parameter selection (Richards et 144 al. 2007). Of course, there are inherent limitations associated with SDMs and interpreting 145 historical distributions should be done cautiously but using SDMs to complement 
Divergence amid recurring gene flow

146 demographic inference is now common in the field of phylogeography (Hickerson et al.

147 2010; Gavin et al. 2014; Peterson and Anamza 2015). Indeed, where a species occurs is

148 determined by its traits and thus genetics. Ikeda et al. (2017) found that SDM predictions

149 under future climate scenarios improved with acknowledgement of local adaptation in

150 Populus fremontii S. Watson (i.e., three identified genetic clusters across the full species

151 distributional range were modeled independently).

153 Here, we focus on two closely related, yet phenotypically diverged, pine species, Table

154 Mountain pine (Pinus pungens Lamb.) and pitch pine (Pinus rigida Mill.). Recent

155 estimates from multiple time-calibrated phylogenies have placed the time of divergence

156 in the range of 1.5 to 17.4 million years ago (mya; Hernandez-Leon et al. 2013; Saladin

157 et al. 2017; Gernandt et al. 2018; Jin et al. 2021), with these studies either placing them

158 as sister species (e.g., Hernandez-Leon et al. 2013; Saladin et al. 2017) or as part of a

159 clade with $P$. serotina Michx. as the sister to $P$. rigida (e.g., Gernandt et al. 2018; Jin et

160 al. 2021). Changes in climate, fire regime, and geographic distributions have likely

161 influenced species divergence (Keeley 2012). This is plausible given that $P$. pungens

162 populations are restricted to high elevations of the Appalachian Mountains, while the

163 much larger distribution of $P$. rigida ranges from Georgia into portions of eastern Canada.

164 It is particularly interesting that these recently diverged species are found in sympatry,

165 yet hybridization has rarely been observed in the field (Zobel 1969), although they can be

166 reciprocally crossed to yield viable offspring (Critchfield 1963). An ecological study of

167 three sympatric $P$. pungens and $P$. rigida populations indicated that the timing of pollen

168 release was separated by approximately four weeks, enough to sustain partial 
Divergence amid recurring gene flow

169 reproductive isolation at these sites (Zobel 1969), which is a common contributor to pre-

170 zygotic isolation among conifer species (Dorman and Barber 1956; Critchfield 1963). It

171 was also noted that while $P$. pungens was most densely populated on arid, rocky, steep

172 southwestern slopes, $P$. rigida was less confined to these areas (Zobel 1969), thus

173 suggesting environmental adaptation may also be important in the divergence of these

174 two closely related species.

175

176 We hypothesized that $P$. pungens and $P$. rigida experienced speciation with gene flow

177 followed by population contraction and isolation (i.e., different refugia) initiated during the

178 LGM. This period of isolation could potentially explain the striking divergence in trait

179 values and phenological schedules between these two species. This hypothesis was

180 assessed and revised using distributional overlap in habitat suitability over the last

181120,000 years and tested using a multidimensional, folded site frequency spectrum from

1822168 genome-wide, unlinked single nucleotide polymorphisms (SNPs) across 300 trees.

183 The SDM-informed hypothesis was supported. Divergence occurred amid ongoing

184 symmetrical gene flow for the past 9.3 - 15.4 million years, depending on generation time,

185 and both species experienced major contraction in effective population size during the

186 LIG. The best supported model also included a reduction in gene flow since the LIG which

187 we sought to explain using population genetic analyses and environmental associations.

188 Prezygotic reproductive isolation due to differing phenological schedules appears to be

189 the primary mechanism involved in the maintenance of species boundaries and an

190 emerging pattern in conifer speciation.

191 
Divergence amid recurring gene flow

194 Methods

195

\section{Sampling}

197 Range-wide samples of needle tissue were obtained from 14 populations of Pinus

198 pungens and 19 populations of Pinus rigida (Fig. 1). Each population consisted of 4-12

199 trees with each sampled tree distanced by approximately $50 \mathrm{~m}$ from the next to avoid

200 potential kinship (Table 1). Needle tissue was dried using silica beads, then approximately

$20110 \mathrm{mg}$ of tissue was cut and lysed for DNA extraction.

202

\section{DNA sequence data}

204 Genomic DNA was extracted from all 300 sampled trees using DNeasy Plant Kits

205 (Qiagen) following the manufacturer's protocol. Four ddRADseq libraries (Peterson et al.

206 2012), each containing up to 96 multiplexed samples, were prepared using the procedure

207 from Parchman et al. (2012). EcoRI and Msel restriction enzymes were used to digest all

208 four libraries before performing ligation of adaptors and barcodes. After PCR, agarose

209 gel electrophoresis was used to separate then select DNA fragments between 300-500

210 bp in length. The pooled DNA was isolated using a QIAquick Gel Extraction Kit (Qiagen).

211 Single-end sequencing was conducted on Illumina HiSeq 4000 platform by Novogene

212 Corporation (Sacramento, CA). Raw fastq files were demultiplexed using GBSX (Herten

213 et al. 2015) version 1.2, allowing two mismatches (-mb 2). The dDocent bioinformatics

214 pipeline (Puritz et al. 2014) was used to generate a reference assembly and call variants. 
Divergence amid recurring gene flow

215 The reference assembly optimized using shell scripts and documentation within dDocent

216 (cutoffs: individual = 6, coverage = 6; clustering similarity: $-\mathrm{c} 0.92)$, utilizing cd-hit-est (Fu

217 et al. 2012) for assembly. The initial variant calling produced 87,548 single nucleotide

218 polymorphisms (SNPs) that was further filtered using vcftools, (Danecek et al. 2011),

219 version 0.1.15. In final, we retained only biallelic SNPs with sequencing data for at least

$22050 \%$ of the samples, minor allele frequency (MAF) $>0.01$, summed depth across samples

$221>100$ and $<10000$, and alternate allele call quality $\varepsilon 50$. To account for linkage

222 disequilibrium, which if not properly acknowledged can lead to erroneous inferences of

223 demographic history (Gutenkunst et al. 2009), we thinned the dataset to one SNP per

224 contig (--thin 100). Additionally, stringent filtering steps to were taken to minimize the

225 potential misassembly of paralogous genomic regions. Removing loci with excessive

226 coverage and retaining only loci with two alleles present, as above, should ameliorate the

227 influence of misassembled paralogous loci in our data (Hapke and Thiele 2016; McKinney

228 et al. 2018). Lastly, we retained loci with $F_{I S}>-0.5$, as misassembly to paralogous

229 genomic regions can lead to abnormal heterozygosity (Hohenlohe et al. 2013; McKinney

230 et al. 2017). The reduced 2168 SNP dataset was used in all analyses.

232 Population structure and genetic diversity

233 Patterns of genetic diversity and structure within and between $P$. pungens and $P$. rigida

234 were assessed using a suite of standard methods. Overall patterns of genetic structure

235 were investigated using principal component analysis (PCA), as employed in the prcomp

236 function of the stats version 4.0.4 package, and population graphs using the popgraph

237 version 1.5.2 package (Dyer and Nason 2004) in R version 3.6.2 (R Development Core 
Divergence amid recurring gene flow

238 Team, 2021). Genetic diversity within each species was examined using multilocus

239 estimates of observed and expected heterozygosity $\left(H_{0}\right.$ and $\left.H_{\mathrm{e}}\right)$ for each population using

240 a custom $\mathrm{R}$ script. An individual-based assignment test was conducted using

241 fastSTRUCTURE (Raj et al. 2014) with cluster assignments ranging from $K=2$ to $K=7$.

242 Ten replicate runs of each cluster assignment were conducted. The cluster assignment

243 with the highest log-likelihood value was determined to be the best fit. Individual

244 admixture assignments were then aligned and averaged across the 10 runs using the

245 pophelper version 1.2 .0 (Francis 2017) package in R. Third, multilocus, hierarchical

246 fixation indices ( $F$-statistics) were defined by nesting trees into populations and

247 populations into species, with $F_{\mathrm{CT}}$ describing differentiation between species and FSC $_{\text {SC }}$

248 describing population differentiation within species (Yang 1998). F-statistics and

249 associated confidence intervals (95\% Cls) from bootstrap resampling ( $n=100$ replicates)

250 were calculated in the hierfstat version 0.5-7 package (Goudet and Jombart 2020) in R.

252 To assess influences on within species genetic structure, Mantel tests (Mantel 1967) were

253 used to examine Isolation-by-Distance (IBD; Wright 1943) and Isolation-by-Environment

254 (IBE; Wang and Bradburd 2014). In these analyses, the Mantel correlation coefficient $(r)$

255 was calculated between linearized, pairwise $F_{S T}$, estimated with the method of Weir and

256 Cockerham (1984) using the hierfstat package in R, and either geographical (IBD) or

257 environmental (IBE) distances. For geographical distances, latitude, and longitude

258 records for each tree in a population were averaged to obtain one representative

259 coordinate per population. Geographic distances among populations were then

260 calculated using the Vincenty (ellipsoid) method within the geosphere version 1.5-10 
Divergence amid recurring gene flow

261 package (Hijmans 2019) in R. Environmental distances were calculated as Euclidean

262 distances using extracted raster values associated with the mean population coordinates

263 from 19 bioclimatic variables, downloaded from WorldClim at 30 arc second resolution

264 (version 2.1; Fick and Hijmans 2017). Values associated with the mean population

265 coordinates for were extracted using the raster version 2.5-7 R package. Environmental

266 data were centered and scaled prior to estimation of distances. Additionally, we used a

267 Mantel test to assess correlation between population-based environmental distances and

268 population-based geographic distances.

Associations between genetic structure and environment

271 To test the multivariate relationships among genotype, climate, and geography,

272 redundancy analysis (RDA) was conducted using the vegan version 2.5-7 package

273 (Oksanen et al. 2020) in R version 4.0.4 (R Core Development Team, 2021). Genotype

274 data were coded as counts of the minor allele for each sample (i.e., 0,1 , or 2 copies) and

275 then standardized following Patterson et al. (2006). Climate raster data (i.e., 19

276 bioclimatic variables at 30 arc second resolutions), as well as elevational raster data from

277 WorldClim, were extracted, as mentioned above, from geographic coordinates for each

278 sampled tree and then tested for correlation using Pearson's correlation coefficient $(r)$.

279 Five bioclimatic variables that were not highly correlated $(r<|0.75|)$ and known to

280 influence diversification in the genus Pinus were retained for analysis: Bio 2 (mean diurnal

281 range), Bio 10 (maximum temperature of the warmest quarter), and Bio 11 (minimum

282 temperature of the coldest quarter), Bio 15 (precipitation seasonality), and Bio 17

283 (precipitation of the driest quarter). The full explanatory data set included these five 
Divergence amid recurring gene flow

284 bioclimatic variables, latitude, longitude, and elevation. The multivariate relationship

285 between genetic variation, climate, and geography was then evaluated through RDA.

286 Statistical significance of the RDA model $(\alpha=0.05)$, as well as each axis within the model,

287 was assessed using a permutation-based analysis of variance (ANOVA) procedure with

288999 permutations (Legendre and Legendre 2012). The influence of predictor variables,

289 as well as their confounded effects, in RDA were quantified using variance partitioning as

290 employed in the varpart function of vegan package in R.

\section{Species distribution modeling}

294 To help formulate a testable hypothesis in the inference of demography from genomic 295 data, species distribution modeling (SDM) was performed for each species to identify 296 areas of suitable habitat under current climate conditions and across three historical time 297 periods (see Richards et al. 2007). These temporal inferences were then used to help 298 identify plausible demographic responses. For example, if overlap in modeled habitat 299 suitability changed over time, the hypothesis for demographic inference would include

300 changes in gene flow parameters over time. If the amount of suitable habitat changed 301 over time, the hypothesis would also include changes in effective population size to allow 302 for potential expansions or contractions. This in effect helps to constrain the possible 303 parameter space for exploration.

305 Occurrence records for $P$. pungens were downloaded from GBIF (www.gbif.org) and 306 combined with known occurrences published by Jetton et al. (2015). For P. rigida, all 
Divergence amid recurring gene flow

307 occurrence records were downloaded from GBIF. Records were examined for presence

308 within or close to the known geographical range of each species (Little 1971). Records

309 far outside the known geographic range were pruned. The remaining locations were then

310 thinned to one occurrence per $10 \mathrm{~km}$ to reduce the effects of sampling bias using the

311 spThin version 0.1.0.1 package (Aiello-Lammens et al. 2015) in R. The resulting

312 occurrence dataset included 84 records for $P$. pungens and 252 records for $P$. rigida

313 (Online Resource 2). All subsequent analyses were performed in $R$ version 3.6 .2 ( $R$

314 Development Core Team, 2021).

316 The same bioclimatic variables (Bio2, Bio10, Bio11, Bio15, Bio17) selected for RDA were

317 used in species distribution modeling but were downloaded from WorldClim version 1.4

318 (Hijmans et al. 2005) at 2.5 arc minute resolution. The change in resolution from above

319 was because paleo-climate data in 30 arc second resolution were not available for the

320 LGM. Paleoclimate raster data for the LGM ( 21,000 years ago) and Holocene (HOL,

321 6000 years ago) were based on three General Circulation Models (GCMs; CCSM4,

322 MIROC-ESM, and MPI-ESM). Ensembles were built by averaging the grid cell values

323 across the three GCMs for each time period, which were then used to predict species

324 distributions and habitat suitability in the past. For comparative purposes, SDMs were

325 also produced from each individual GCM for each time period since the LGM.

326 Paleoclimate data for the LIG ( 120,000 years ago; Otto-Bliesner et al. 2006) were only

327 available at 30 arc second resolution and required downscaling to 2.5 arc minute

328 resolution using the aggregate function (fact=5) of the raster package. Only one GCM is

329 available for the LIG; therefore, no ensemble was built. 
Divergence amid recurring gene flow

331 Raster layers were cropped to the same extent using the raster package to include the

332 most northern and eastern extent of $P$. rigida, and the most western and southern extent

333 of $P$. pungens. Species distribution models (SDMs) were built using MAXENT version 3.4.1

334 (Phillips et al. 2017) and all possible features and parameter combinations were

335 evaluated using the ENMeval version 2.0.0 R package (Kass et al. 2021). Metadata

336 about model fitting and evaluation are available within Online Resource 2.

338 The selected features used in predictive modeling were those associated with the best-

339 fit model as determined using AIC. Raw raster predictions were standardized to have the

340 sum of all grid cells equal the value of one using the raster.standardize function in the

341 ENMTools version 1.0.5 (Warren et al. 2021) R package. Standardized predictions were

342 then transformed to a cumulative raster prediction with habitat suitability scaled from 0

343 to 1, allowing for quantitative SDM comparisons across species and time. Next, SDM

344 cumulative raster predictions were converted into coordinate points using the sf version

$345 \quad 0.9-7 \mathrm{R}$ package to calculate the number of points with habitat suitability values greater

346 than 0.5 (i.e., moderate to high suitability areas). Population size expansion or

347 contraction was hypothesized if the number of points increased or decreased over time,

348 respectively. Overlap (i.e., shared points across species) in SDM predictions for each

349 time period was measured using the inner join function in the dplyr version 1.0.5 R

350 package. The extent of modeled species distributional overlap was also quantified using

351 the raster.overlap function in ENMTools, thus providing measures for Schoener's $D$

352 (1968) and Warren's I (Warren et al. 2008). 
Divergence amid recurring gene flow

\section{Demographic modeling}

355 Demographic modeling was conducted using Diffusion Approximation for Demographic 356 Inference ( $\partial \alpha \partial i$ v.2.0.5; Gutenkunst et al. 2009). A model of pure divergence (SI; strict

357 isolation) was compared against eleven other demographic models representing different

358 potential divergence scenarios with or without gene flow and effective population size 359 changes (Online Resource 4, Fig. S4). Based on SDM predictions across four time points, 360 we hypothesized that a model that allowed changes in effective population size and rate 361 of gene flow before the LIG would best fit the genetic data. Ten replicate runs of each 362 model were performed in $\partial \alpha \partial i$ with a $200 \times 220 \times 240$ grid space and the nonlinear 363 Broyden-Fletcher-Goldfarb-Shannon (BFGS) optimization routine. Model selection was 364 conducted using Akaike information criterion (AIC; Akaike 1974). The best replicate run 365 (highest log composite likelihood) for each model was then used to calculate $\triangle$ AIC 366 (AIC modeli - AIC best model) scores (Burnham and Anderson 2002). From the best supported 367 model, upper and lower 95\% confidence intervals (Cls) for all parameters were obtained 368 using the Fisher Information Matrix (FIM)-based uncertainty analysis. Unscaled 369 parameter estimates and their $95 \%$ Cls were obtained using a per lineage substitution 370 rate of $7.28 \times 10^{10}$ substitutions/site/year rate for Pinaceae (De La Torre et al. 2017) and 371 two possible values for generation time, 15 and 25 years, for comparative purposes. 
Divergence amid recurring gene flow

376

377

378

379

380

381

382

383

384

385

386

387

388

389

390

391

392

393

394

395

396

397

\section{Results}

\section{Population structure and genetic diversity}

Principal component analysis (PCA) showed clear separation at the species level along PC1 which explained $4.232 \%$ of the variation across the 2168 SNP $\times 300$ tree data set (Fig. 2a). Of the 2168 SNPs analyzed, 380 and 196 SNPs were fixed in P. pungens and P. rigida, respectively. Lack of population clustering within each species was observed when the PCA was labeled by population (Online Resource 4, Fig. S1). Using hierarchical $F$-statistics, the estimate of differentiation between species $\left(F_{\mathrm{CT}}\right)$ was $0.117(95 \% \mathrm{Cl}$ : $0.099-0.136)$ and similarly to that among all sampled populations $\left(F_{\mathrm{ST}}=0.123,95 \% \mathrm{Cl}\right.$ : $0.106-0.143)$, thus highlighting structure is largely due to differences between species. Differentiation among populations within species was consequently much lower $\left(F_{\mathrm{SC}}=\right.$ 0.007 (95\% Cl: $0.0055-0.0088)$ whether analyzed jointly ( $\left.F_{S C}\right)$ or separately (see Table 2). In the analysis of structure, $K=2$ had the highest log-likelihood values (Fig. 2b). Admixture in small proportions (assigning to the other species by 2-10\%) was observed in 41 out of the 300 samples (13.67\% of samples) across both species. There were 16 trees with ancestry coefficients higher than $10 \%$ assignment to the other species: four $P$. rigida samples $(2.29 \%$ of sampled $P$. rigida) and twelve $P$. pungens samples $(9.60 \%$ of sampled $P$. pungens). Admixture proportions were moderately correlated to latitude (Pearson's $r=-0.414$ ), longitude (Pearson's $r=-0.291$ ), and elevation (Pearson's $r=$ 0.445). All three correlative relationships were significant $(p<0.001)$. 
Divergence amid recurring gene flow

398 Pairwise $F_{\text {ST }}$ estimates for $P$. pungens ranged from 0 to 0.0457 , while a similar but 399 narrower range of values $(0-0.0257)$ was noted for $P$. rigida. The highest pairwise $F_{\text {ST }}$

400 value across both species was between two $P$. pungens populations located in Virginia, 401 PU_DT and PU_BB (Table 1). Interestingly, PU_DT in general had higher pairwise FST 402 values $(0.0146-0.0457)$ compared to all the other sampled $P$. pungens populations 403 (Online Resource 1). For P. rigida, the RI_SH population located in Ohio had higher 404 pairwise $F_{S T}$ values for 16 out of the 18 comparisons $(0.0123-0.0257)$. The two 405 populations that had low pairwise FST values with RI_SH were geographically nearby: 406 RI_OH located in Ohio (pairwise $F_{S T}=0$, distance: $90.1 \mathrm{~km}$ ) and RI_KY located in 407 Kentucky (pairwise $F_{\text {ST }}=0.0089$, distance: $107.7 \mathrm{~km}$ ). The highest pairwise $F_{\text {ST }}$ value 408 among $P$. rigida populations was between $\mathrm{RI}$ _SH and $\mathrm{RI} H \mathrm{H}$, which are geographically 409 distant from one another. From the Mantel tests for IBD and IBE, Pearson correlations 410 were low (Table 2). The correlation with geographical distances was highest for $P$. rigida 411 (Mantel $r=0.176, p=0.055)$. From the Mantel test, Pearson correlation between 412 geographic distance and environmental distance was high for both $P$. rigida $(r=0.611, p$ $413=0.001)$ and $P$. pungens $(r=0.893, p=0.001)$. Observed heterozygosity of $P$. pungens $414\left(H_{0}=0.127 \pm 0.015 \mathrm{SD}\right)$, averaged across SNPs and populations, was higher than the 415 average expected heterozygosity $\left(H_{\mathrm{e}}=0.118 \pm 0.008 \mathrm{SD}\right)$, both of which were higher than 416 the almost equal values for $P$. rigida $\left(H_{0}=0.102 \pm 0.009 \mathrm{SD} ; H_{\mathrm{e}}=0.104 \pm 0.005 \mathrm{SD}\right.$; 417 Table 2). Heterozygosity estimates for each population are listed in Table 1. Across both 418 species, observed heterozygosity was mildly associated with geography and elevation. 419 For $P$. rigida, the highest correlation was with elevation $(r=0.253)$, followed by correlation 420 with longitude $(r=0.113)$. Observed heterozygosity in $P$. pungens had a negative 
Divergence amid recurring gene flow

421 correlative relationship with elevation $(r=-0.168)$ and positive correlative relationship with

422 longitude $(r=0.175)$. Correlations between latitude and heterozygosity were low in both

423 species ( $r=0.008$ for $P$. rigida; $r=0.08$ for $P$. pungens).

425 Population graphs provide a visualization of the relative genetic connectivity across and 426 among populations, as well as the relative genetic diversity within each population. Edges

427 in population graphs represent unique associations in allele frequencies between

428 populations. Collinearity across measures of genetic connectivity between populations,

429 or across species labels, leads to edges being dropped from the population graph.

430 Consistent with the PCA, fastSTRUCTURE, and F-statistics results, two disjunct groups

431 of populations were apparent in the population graph, with each group largely

432 corresponding to species labels (Fig. 3). The exception was the PU_DT population from

$433 P$. pungens, which is located in Virginia, that showed genetic connectivity with two 434 geographically distant populations from $P$. rigida, located in Ohio (RI_SH) and Maine 435 (RI_ME).

438 Associations between genetic structure and environment

439 The combined effects of climate and geography explained $4.16 \%\left(r^{2}\right)$, or rather $1.52 \%$

$440\left(\operatorname{adj} . r^{2}\right)$, of the genetic variance across 2168 SNPs and 300 sampled trees. The first RDA

441 axis accounted for the bulk of the explanatory variance (42.3\%, Fig. 4) and was the only

442 RDA axis with a $p$-value $(p<0.001)$ less than commonly accepted thresholds of

443 significance. Average elevation associated with $P$. pungens samples was $724.68 \mathrm{~m}( \pm$ 
Divergence amid recurring gene flow

444 224.17 SD), while average elevation across $P$. rigida samples was lower (399.69 m, \pm 445292.26 SD). The average for Bio15 (precipitation seasonality) was 11.33 ( \pm 1.83 SD) for $446 P$. pungens, and higher for $P$. rigida (14.23 \pm 3.97 SD). Precipitation seasonality is the

447 coefficient of variation calculated from monthly mean precipitation values across the span 448 of one year. Considering the standard deviations around the mean, overlap in values for 449 elevation and precipitation seasonality provide some context to present day overlap in 450 species distributions along the southern Appalachian Mountains. Comparisons of

451 predictor loadings across both RDA axes show latitude, longitude, and Bio11 (mean 452 temperature of the coldest quarter) as important to explaining the variance both within 453 (RDA 2, 9.77\%) and across species (RDA1).

455 Partitioning the effects of each predictor set revealed that climate independently (i.e., 456 conditioned on geography) accounted for $31.93 \%$ of the explained variance. Geography 457 independently (i.e., conditioned on climate) accounted for $34.10 \%$ of the explained 458 variance. The confounded effect, due to the correlations inherent to the chosen 459 geographic and climatic predictor variables, was 33.97\%.

\section{$461 \quad$ Species distribution modeling}

462 Past geographical distributions during the LIG, LGM, and HOL were predicted using 463 MAXENT to form testable hypotheses within the demographic inference framework of $464 \partial \alpha \partial i, v .2 .0 .5$. Because population structure within each of the focal species was not 465 observed from our genetic data (i.e., no genetic clusters were identified), we produced 466 SDMs using occurrence records across the full distributional range of each species. The 
Divergence amid recurring gene flow

467 best fit SDM for $P$. pungens used a linear and quadratic feature class with a 1.0 468 regularization multiplier, while the SDM for $P$. rigida used a linear, quadratic, and hinge

469 feature class with a regularization multiplier of 3.0. Best-fit models were those with the 470 lowest AIC when evaluated against other models with varying feature class and 471 regularization multiplier settings. The AUC associated with the training data of the $P$. 472 pungens and $P$. rigida SDMs was 0.929 and 0.912 , respectively. Metadata, data inputs, 473 outputs, and statistical results for model evaluation are available in Online Resource 2.

474 The climatic variables with the highest permutation importance were Bio11 (mean 475 temperature of the coldest quarter) and Bio15 (precipitation seasonality) which 476 contributed $41.1 \%$ and $39.7 \%$ to the $P$. pungens SDM and $19.5 \%$ and $62.4 \%$ to the $P$. 477 rigida SDM. Of the five climate variables included in the RDA, Bio15 and Bio11 had the 478 highest loadings along RDA axis 1, helping to explain differences across species. The 479 tandem reporting of Bio15 and Bio11 importance to both genetic differentiation and 480 species distributions could be indicative that these climatic variables were drivers in the 481 divergence of these two species.

483 Current SDMs indicate a larger area of suitable habitat for $P$. rigida $(11,128 \mathrm{grid}$ cells had $484>0.5$ habitat suitability) compared to $P$. pungens $(6,632$ grid cells) with the highest overlap 485 (14.07\% shared cells) across all four time points (Fig. 5). According to the SDM 486 predictions, the areas of moderate to high suitability shifted, contracted, and expanded 487 over time for both species, with overlapping areas of suitable habitat exhibiting some of 488 these fluctuations as well. SDM predictions for HOL indicate the lowest overlap (8.25\% 489 of grid cells with $>0.5$ habitat suitability), while LGM predictions indicate the highest 
Divergence amid recurring gene flow

490 overlap (16.33\%). Contrastingly, calculations of overlap from full distributional predictions

491 were the lowest (Schoener's $D=0.170$ ) for LGM followed by the LIG (Schoener's $D=$

492 0.288). The highest full distributional overlap was associated with the current SDM

493 (Schoener's $D=0.612$ ).

495 The ensemble prediction for $P$. pungens during the LGM shows multiple potential refugial 496 areas. One of these areas may have been glaciated (Fig. 5). Likewise, multiple refugia

497 were predicted for $P$. rigida during the LGM, but these areas were below the mapped 498 glacial extent ( 18 kya; Dyke 2003). Interspecific gene flow during the LGM may thus 499 have been possible just south of the glacial extent as well as in a disjunct refugia farther 500 south than where either species currently occurs. Modeled distributions of $P$. pungens 501 and $P$. rigida during the $\mathrm{HOL}$ distributions were proximal to each other, with high habitat 502 suitability west of and along the Appalachian Mountains. These distributions may have 503 promoted both intraspecific and interspecific gene flow to occur $\sim 6$ kya. The above 504 quantifications are based on the SDM predictions from ensembled GCMs for the HOL 505 and LGM time periods. SDM predictions associated with each independent GCM 506 (CCSM4, MIROC-ESM, and MPI-ESM) are available in Online Resource 4 (Fig. S2, Fig. 507 S3).

\section{Demographic modeling}

510 Results from the SDMs and fastSTRUCTURE analysis informed the hypothesis that

511 divergence occurred with ongoing gene flow given the overlap in suitable habitat across 512 the four time points. Gene flow was hypothesized to be symmetrical given the rather even 
Divergence amid recurring gene flow

513 distribution in admixture Q-scores across both species (Fig. 2). We further hypothesized

514 effective population sizes to have been stable over the past 120,000 years as potentially

515 impactful expansion or contraction in habitat suitability was not observed. The best

516 replicate run (highest composite log-likelihood) for each of the twelve modeled divergence

517 scenarios, their associated parameter outputs, and $\triangle \mathrm{AIC}(\mathrm{AIC}$ model i $-\mathrm{AIC}$ best model $)$ are

518 summarized in Online Resource 3. A model that allowed changes in both effective

519 population size and rate of symmetrical gene flow across two time periods (PSCMIGCs)

520 best fit the 2168 SNP data set (Table 2) and had small, normally distributed residuals

521 (Fig. S5). This model was 20.84 AIC units better than the second best-fit model

522 (PSCMIGs; Table 3), which had allowed change in population size estimates across two

523 time intervals but only one symmetrical gene flow parameter was inferred, representing

524 a constant rate across both time periods.

525

526 Assuming a generation time of 15 years, the unscaled parameters from the best-fit model

527 estimated an initial divergence time at 9.27 mya $(95 \% \mathrm{Cl}: 7.60-10.94)$. With a $25-$ year

528 generation time, initial divergence was estimated to be 15.44 mya (95\% Cl: 12.64 -

529 18.24). The first time interval during divergence $\left(T_{1}\right)$ lasted $98.7 \%$ of the total divergence

530 time with symmetrical gene flow $\left(M_{i}\right)$ occurring at a rate of $48.6(95 \% \mathrm{Cl}: 33.1-64.1)$

531 migrants per generation (Fig. 6). Parameters associated with effective population size

532 were independent of generation time. The effective size of the ancestral population (Nref)

533 was 203,431 (95\% Cl: 176,575 - 230,287; Fig. 6) prior to divergence. For most of the

534 divergence history, $P$. pungens had an effective population size of $N_{P 1}=5,767,720(95 \%$

535 Cl: $791,500-10,743,940)$ while $P$. rigida had a relatively smaller, but still large, effective 
Divergence amid recurring gene flow

536 size of $N_{R 1}=4,272,253(95 \% \mathrm{Cl}: 1,207,070-7,337,436)$. The second time interval $\left(T_{2}\right)$

537 during divergence was estimated to have begun between 118,897 (15 year generation

538 time; 95\% Cl: 111,400 - 126,394) and 198,115 (25 year generation time; 95\% Cl: 185,622

$539-210,608)$ years ago when effective population sizes decreased instantaneously to

$54019,408\left(95 \% \mathrm{Cl}: 18,160\right.$ - 20,656) for P. pungens $\left(N_{P 2}\right)$ and 22,151 (95\% Cl: $20,710-$

$54123,592)$ for $P$. rigida $\left(N_{R 2}\right)$. During this time interval the relative rate of symmetrical gene

542 flow dropped from 48.6 to $38.4(95 \% \mathrm{Cl}: 35.7-41.1)$ migrants per generation.

\section{Discussion}

547 To understand the divergence history and development of reproductive isolation between

$548 P$. pungens and $P$. rigida, we combined inferences of population structure, admixture,

549 environmental associations, and historical species distribution modeling to form a testable

550 hypothesis within a demographic inference framework. Our hypothesis was supported.

551 Since the LIG, effective population sizes for both species did not change, and interspecific

552 gene flow continued to occur. The best-fit demographic model using 2168 SNPs as

553 summarized using the multidimensional site frequency spectrum also indicated that at the

554 onset of the LIG there was a large reduction in effective population size which coincided

555 with a reduction in gene flow. Even though gene flow occurred throughout the history of

556 these two species, distinctive life histories and phenotypes have developed. The

557 morphology and distributional differences across $P$. pungens and $P$. rigida suggest 
Divergence amid recurring gene flow

558 divergence was driven by fire and climate with phenological differences contributing to

559 the maintenance of species boundaries through partial, prezygotic reproductive isolation.

\section{Climate drives divergence}

563 Adaptation to seasonality among temperate species was influenced by Quaternary

564 climate (Dobzhansky 1950; Savolainen et al. 2004; Jump and Penuelas 2005; Williams

565 and Jackson 2007; Bonebrake and Mastrandea 2010). Phenological traits have been

566 linked to seasonal variation within species of North America (Jump and Penuelas 2005),

567 and differences in seasonality requirements for $P$. pungens and $P$. rigida likely explain the

568 observed phenological trait differences in seed size, reproductive age, timing of pollen

569 release, and rates of seedling establishment across these two species (Zobel 1969; Della-

570 Bianca 1990; Ledig et al. 2015). Using niche and trait data, the phylogenetic inference of

571 Jin et al. (2021) identified precipitation seasonality (Bio15) and elevation as drivers of

572 diversification in eastern North American pines. The results of our RDA corroborate these

573 conclusions, as clear separation of species-level genetic differences was explained by

574 Bio15 and elevation along axis 1 (Fig. 4). Quaternary climate began 2.6 mya and in terms

575 of the total divergence time inferred for these two species ( $9.3-15.4$ mya) adaptations

576 to seasonality occurred rather recently ( 16 $-25 \%$ of total divergence time). Based on

577 our data, $P$. pungens has lower and narrower niche requirements in terms of Bio15, which

578 helps explain its patchy distribution along the southern Appalachian Mountains. In

579 contrast, populations of $P$. rigida may have evolved a response to increased precipitation 
Divergence amid recurring gene flow

580 seasonality during the Quaternary period, explaining its larger distribution and latitudinal

581 expansion into northeastern North America.

583 Divergence between $P$. pungens and $P$. rigida began during the Miocene between 9.3

584 and 15.4 mya, which is consistent with divergence times previously estimated for these

585 two pine species (Gernandt et al. 2018; Jin et al. 2021). The evolution of fire-related traits

586 in pines has been linked to the mid-Miocene period (Jin et al. 2021) suggesting fire as an

587 initiator of differentiation across ancestral populations. Distributions of our focal species

588 are locally divergent across slope aspects in the Appalachian Mountains, with P. pungens

589 primarily distributed on southwestern slopes and $P$. rigida primarily distributed on

590 southeastern slopes (Zobel 1969). Due to higher fire frequency and intensity on western

591 slopes, $P$. pungens has evolved strategies that confer population persistence such as

592 high cone serotiny and fast seedling development. Although some northern $P$. rigida

593 populations exhibit serotiny, the populations found along the southern Appalachian

594 Mountains, and proximal to $P$. pungens, have nonserotinous cones and other traits

595 consistent with enduring fire (e.g., epicormics; Zobel 1969) as opposed to relying on it

596 (Jin et al. 2021). With these factors in mind and the correlative evidence between fire

597 intensity and level of serotiny presented across populations of other pine species $(P$.

598 halepensis and $P$. pinaster; Hernandez-Serrano et al. 2013), we suspect genomic regions

599 involved in the complex, polygenic trait of serotiny (Parchman et al. 2012; Budde et al.

600 2014) may have contributed to the rapid development of prezygotic reproductive isolation

601 between our focal species.

602 
Divergence amid recurring gene flow

\section{Reproductive isolation can evolve rapidly during conifer speciation}

604 While $P$. pungens and $P$. rigida can be found on the same mountain and even established

605 within a few meters of each other, mountains are heterogeneous, complex landscapes

606 offering opportunity for niche evolution along multiple axes of biotic and abiotic influence

607 for parental species and hybrids alike. The distances to disperse into novel environments

608 are relatively short in these heterogenous landscapes thus suggesting diversification

609 could be more rapid as environmental complexity increases (Bolte and Eckert 2020).

610 Mountains have rain shadow regions characterized by drought and thus more active fire

611 regimes (Parisien and Moritz 2009). A host of adaptive traits in trees are associated with

612 fire frequency and intensity (Pausas and Schwilk 2012). Among those, the genetic basis

613 of serotiny is characterized as being polygenic with large effect loci in $P$. contorta Dougl.

614 (Parchman et al. 2012) and in P. pinaster Aiton (Budde et al. 2014). Such genetic

615 architectures, even in complex demographic histories such as the one described here,

616 can evolve relatively rapidly to produce adaptive responses to shifting optima (e.g., Stetter

617 et al. 2018; reviewed for forest trees by Lind et al. 2018), so that it is not unreasonable to

618 expect divergence in fitness-related traits such as serotiny to also contribute to niche

619 divergence and reproductive isolation. Considering large effect loci associated with

620 serotiny were also associated with either water stress response, winter temperature, cell

621 differentiation, or root, shoot, and flower development (Budde et al. 2014), serotiny may

622 be a trait that contributes to widely distributed genomic islands of divergence thus

623 explaining the development of ecologically based reproductive isolation between $P$.

624 pungens and $P$. rigida amid recurring gene flow (Nosil and Feder 2012). Given that our

625 focal species are reciprocally crossable to yield viable offspring (Critchfield 1963), it is 
Divergence amid recurring gene flow

626 likely that postzygotic ecological processes, such as selection for divergent fire-related

627 and climatic niches limits hybrid viability in natural stands. Indeed, hybrids are rarely

628 identified in sympatric stands (Zobel 1969; Brown 2021). Thus, it appears that niche

629 divergence is associated with divergence in reproductive phenologies during speciation

630 for our focal taxa. However, whether niche divergence reinforces reproductive isolation

631 based on pollen release timing or divergent pollen release timing is an outcome of niche

632 divergence itself remains an open question.

634 The rate of symmetrical gene flow in our best-fit demographic model was reduced by

635 approximately 10 migrants per generation providing evidence that prezygotic 636 reproductive isolation may have strengthened under Quaternary climatic conditions. This

637 reduction reflects a scenario of reduced effective population sizes, reduced rates of

638 migration $(m)$, or both. The rate of gene flow associated with a given time interval should 639 not be interpreted as constant though. Sousa et al. (2011) found that posterior 640 distributions for the timing of gene flow parameters in demographic inference were highly 641 variable across the simulations they performed making pulses of gene flow (i.e., a gene 642 flow event occurring within a time frame of no active gene flow), as probable as constant, 643 ongoing gene flow. While acknowledging this blurs interpretation of parameter estimates 644 for gene flow, a history with recurring gene flow events fits the narrative of prezygotic 645 isolation being labile especially when geographical distributions or reproductive 646 phenology are the factors involved. Indeed, observations of hybridization occurring 647 between once-prezygotically isolated species have been made and suggests 648 phenological barriers such as timing of pollen release and flowering may not be 
Divergence amid recurring gene flow

649 permanently established and can shift towards synchrony in warming climates (Vallejo-

650 Marín and Hiscock 2016).

\section{Climate instability reduces genetic diversity}

653 Conifers often have high genetic diversity and low population differentiation because of 654 outcrossing, wind-dispersion, and introgression (Petit and Hampe 2006). Pinus pungens

655 and $P$. rigida both have modest levels of genetic diversity within and across the 656 populations we sampled, and no detectable within-species population structure given our 657 genome-wide data. Our best fit model inferred a drastic effective population size reduction 658 (P. pungens, $~ 99.7 \%$; $P$. rigida, $~ 99.5 \%)$ between 118-198 kya. Since then, climate has 659 continued to oscillate between glacial and interglacial periods for geologic time intervals 660 too short for species with long generation times and low migratory potential to sufficiently 661 track causing a mismatch between the breadth of a species' climatic niche and where 662 populations are established (Svenning et al. 2015). This dynamic affects population 663 persistence, reduces genetic variation within populations, and thus to some degree limits 664 the potential for local adaptation in climatically unstable regions and may explain the lack 665 of IBD and IBE across the populations of our focal species. Our SDM predictions showed 666 substantial shifts in habitat suitability since the LIG providing evidence of high climate 667 instability in temperate eastern North America during the Quaternary period.

669 From a theoretical standpoint, we anticipated the patchy, mountain top distribution of $P$.

670 pungens to be characterized by strong patterns of population differentiation. Lack of 671 structure in $P$. pungens could be attributed to long distant dispersal or a recent move up 
Divergence amid recurring gene flow

672 in elevation with genomes still housing elements of historical panmixia. Indeed, suitable

673 habitat predictions during the HOL, just 6000 years ago, were rather contiguously

674 distributed (Fig. 5) and may have allowed an increase in intraspecific gene flow. For $P$.

675 rigida some structure differentiating the northern populations from those along the

676 southern Appalachian Mountains was expected from an empirical standpoint because

677 previously reported trait values in a common garden study led to identification of three

678 latitudinally arranged genetic groupings (Ledig et al. 2015). Although structure analysis

679 did not support groupings within $P$. rigida, our estimates for isolation-by-distance (IBD)

680 yielded a correlation of $0.177(p=0.055)$ which is suggestive of structure. While this

681 shows some differentiation across its distribution, pairwise $F_{S T}$ values were small and on

682 average smaller than those between populations of $P$. pungens suggesting higher

683 population connectivity in $P$. rigida. The SDM prediction for $P$. rigida during the LGM

684 indicated three regions with high habitat suitability: a large region farther south than where

685 it is currently distributed, one just east of the Appalachian Mountains, and another just

686 south of the Laurentide ice sheet. While genetic differences may have accumulated in

687 these separate refugia, the SDM prediction for the HOL were more compact and 688 contiguous for $P$. rigida, as was similarly observed for $P$. pungens, thus providing greater 689 potential for intraspecific gene flow across diverged populations.

\section{$691 \quad$ Future work and conclusions}

692 Conifers, especially pines, have large and complex genomes (> $20 \mathrm{Gbp}$ ), so it is important

693 to first understand their demographic history, the prevalence of interspecific gene flow 694 historically and currently, and the role climate and geography may have played in shaping 
Divergence amid recurring gene flow

695 standing levels of genetic diversity before expending valuable resources into a more

696 elaborate genomic research endeavor. The divergence history of $P$. pungens and $P$.

697 rigida involved a complex interplay of recurring interspecific gene flow and dramatic

698 population size reductions associated with changes in climate. We suspect that low

699 population differentiation within each species is linked to climate instability and the

700 mismatch between being long-lived, sessile species struggling to track rapidly shifting

701 climatic optima during complex demographic scenarios and that prezygotic isolating

702 barriers linked to reproductive phenology are involved in the maintenance of species

703 boundaries. The results of our demographic inference warrant more research into these

704 two species and other coniferous species of this region. No studies to date have inferred

705 divergence histories for pine species native to eastern North America, and to our

706 knowledge, only one other inference for conifer speciation has been conducted for this

707 region, Picea mariana and $P$. rubens, and it was an interesting, rare account for

708 progenitor-derivative speciation (Perron et al. 2000). Future detailed examinations of

709 hybridization between $P$. pungens and $P$. rigida are needed to elucidate the role

710 hybridization plays (e.g., adaptive or reinforcing) in the maintenance of species

711 boundaries and identify environmental associations with hybrid establishment (e.g.,

712 mountain aspect and elevation). Ideally, future research involving these two species

713 would use a method that sufficiently captures genic regions so population structure in

714 both species may be revealed and investigations into genomic islands of divergence that

715 are often associated with ecological speciation can be performed (Nosil and Feder 2012). 
Divergence amid recurring gene flow

717 While more time, effort, and genomic resources are needed for us to accurately predict

718 gains and losses in biodiversity or describe the development of reproductive isolation in

719 conifer speciation, we must recognize that some montane conifer species will be

720 disproportionally affected by future climate projections (Aitken et al. 2008) and time is of

721 the essence in terms of capturing and understanding current levels of biodiversity. High

722 elevational species such as $P$. pungens may already be experiencing a tipping point, but

723 because $P$. pungens is a charismatic Appalachian tree with populations already

724 threatened by fire suppression practices over the last century, conservation efforts have

725 begun through seed banking (Jetton et al. 2015) and prescribed burning experiments of

726 natural stands (Welch and Waldrop 2001). Our contributions to these conservation efforts

727 include genome-wide population diversity estimates for $P$. pungens and $P$. rigida and a

728 demographic inference scenario that involves a long history of interspecific gene flow and

729 hybridization. In conifer species of the family Pinaceae, there are multiple accounts of

730 introgression occurring through hybrid zones (De La Torre et al. 2014; Hamilton et al.

731 2015; Menon et al. 2018). The implications of introgression are far-reaching as it leads to

732 greater genetic diversity and thus a greater capacity for adaptive evolution. Trees are

733 keystone species, so understanding a population's potential to withstand environmental

734 changes provides some insight into the future stability of an ecosystem.

735

736

737

738

739

740

741

742

743

744

\section{Author contributions}

CB performed field sampling of Pinus rigida, data analyses, and modeling. TF processed the genetic data and advised statistical analyses. CF led the field sampling and library prep for Pinus pungens, and AJE assisted with data analyses. All authors contributed to the writing of this manuscript. 
Divergence amid recurring gene flow

\section{Data Archiving Statement}

Raw reads generated during this study are available at NCBI SRA database under BioProject: PRJNA803632 (Sample IDs: SAMN25684544 - SAMN25684843). Python scripts for demographic modeling and R scripts for genetic analyses and producing SDMs are available at www.github.com/boltece/Speciation_2pines.

\section{Supplemental material:}

Online Resource 1: Summary statistics per SNP, sampled tree, and population

Online Resource 2: Metadata and files needed to reproduce SDMs

Online Resource 3: Results from demographic inference and parameter unscaling Online Resource 4: Supplemental figures

\section{References:}

Abbott RJ (2017) Plant speciation across environmental gradients and the occurrence and nature of hybrid zones. J Syst Evol 55:238-258. https://doi.org/10.1111/ise.12267

Aiello-Lammens ME, Boria RA, Radosavljevic A, et al (2015) spThin: An R package for spatial thinning of species occurrence records for use in ecological niche models. Ecography 38:541-545. https://doi.org/10.1111/ECOG.01132

Aitken SN, Yeaman S, Holliday JA, et al (2008) Adaptation, migration or extirpation: climate change outcomes for tree populations. Evol Appl 1:95-111. https://doi.org/10.1111/J.1752-4571.2007.00013.X

Baack E, Melo MC, Rieseberg LH, Ortiz-Barrientos D (2015) The origins of reproductive isolation in plants. New Phytol 207:968-984. https://doi.org/10.1111/NPH.13424

Bagley JC, Heming NM, Gutiérrez EE, et al (2020) Genotyping-by-sequencing and ecological niche modeling illuminate phylogeography, admixture, and Pleistocene range dynamics in quaking aspen (Populus tremuloides). Ecol Evol 10:4609-4629. https://doi.org/10.1002/ece3.6214

Bolte CE, Eckert AJ (2020) Determining the when, where and how of conifer speciation: a challenge arising from the study 'Evolutionary history of a relict conifer Pseudotaxus chienii.' Ann Bot 125:v-vii. https://doi.org/10.1093/AOB/MCZ201

Bonebrake TC, Mastrandrea MD (2010) Tolerance adaptation and precipitation changes complicate latitudinal patterns of climate change impacts. Proc Natl Acad Sci U S A 107:12581-12586. https://doi.org/10.1073/pnas.0911841107 
Divergence amid recurring gene flow

783

784

785

786

787

788

789

790

791

792

793

794

795

796

797

798

799

800

801

802

803

804

805

806

807

808

809

810

811

812

813

814

815

816

Brown AL (2021) Phenotypic characterization of Table Mountain (Pinus pungens) and pitch pine (Pinus rigida) hybrids along an elevational gradient in the Blue Ridge Mountains, Virginia. Thesis, Virginia Commonwealth University

Cannon CH, Petit RJ (2020) The oak syngameon: more than the sum of its parts. New Phytol 226:978-983. https://doi.org/10.1111/nph.16091

Capblancq T, Butnor JR, Deyoung S, et al (2020) Whole-exome sequencing reveals a long-term decline in effective population size of red spruce (Picea rubens). Evol Appl 13:2190. https://doi.org/10.1111/EVA.12985

Carstens BC, Richards CL (2007) Integrating coalescent and ecological niche modeling in comparative phylogeography. Evolution 61:1439-1454. https://doi.org/10.1111/J.1558-5646.2007.00117.X

Cavender-Bares J (2019) Diversification, adaptation, and community assembly of the American oaks (Quercus), a model clade for integrating ecology and evolution. New Phytol 221:669-692. https://doi.org/10.1111/nph.15450

Christe C, Stölting KN, Paris M, et al (2017) Adaptive evolution and segregating load contribute to the genomic landscape of divergence in two tree species connected by episodic gene flow. Mol Ecol 26:59-76. https://doi.org/10.1111/mec.13765

Critchfield WB (1963) The Austrian x red pine hybrid. Silvae Genet12:187-191

Critchfield WB (1967) Crossability and relationships of the closed-cone pines. Silvae Genet 16:89-97

Critchfield WB (1986) Hybridization and Classification of the White Pines (Pinus Section Strobus). Taxon 35:647-656

Danecek P, Auton A, Abecasis G, et al (2011) The variant call format and VCFtools. Bioinformatics 27:2156-2158. https://doi.org/10.1093/bioinformatics/btr330

De La Torre AR, Birol I, Bousquet J, et al (2014) Insights into conifer giga-genomes. Plant Physiol 166:1724-1732. https://doi.org/10.1104/pp.114.248708

De La Torre AR, Li Z, Van De Peer Y, Ingvarsson PK (2017) Contrasting rates of molecular evolution and patterns of selection among gymnosperms and flowering plants. Mol Biol Evol 34:1363-1377. https://doi.org/10.1093/molbev/msx069

Della-Bianca L (1990) Pinus pungens Lamb., Table Mountain pine. In: Burns, R.M. and B.H. Honkala (eds.). Silvics of North America. Volume 1. Conifers. USDA Forest Service Agriculture Handbook 654, Washington, D.C.

Dobzhansky T (1950) Heredity, Environment, and Evolution. Assoc Adv Sci 111:161- 
Divergence amid recurring gene flow

166. https://doi.org/10.1126/science.111.2877.161

Dorman KW, Barber JC (1956) Time of flowering and seed ripening in southern pines. USDA Forest Service, Southeastern Forest Experiment Station, Old Station Paper SE-072, 72.

Dyer RJ, Nason JD (2004) Population Graphs: The graph theoretic shape of genetic structure. Mol Ecol 13:1713-1727. https://doi.org/10.1111/J.1365294X.2004.02177.X

Dyke AS, Moore A, Robertson L (2003) Deglaciation of North America, Open File 1574, Natural Resources Canada, Ottawa.

Fick SE, Hijmans RJ (2017) WorldClim 2: new 1-km spatial resolution climate surfaces for global land areas. Int J Climatol 37:4302-4315. https://doi.org/10.1002/JOC.5086

Francis RM (2017) pophelper: an R package and web app to analyse and visualize population structure. Mol Ecol Resour 17:27-32. https://doi.org/10.1111/1755-0998.12509

Fu L, Niu B, Zhu Z, et al (2012) CD-HIT: Accelerated for clustering the next-generation sequencing data. Bioinformatics 28:3150-3152. https://doi.org/10.1093/bioinformatics/bts565

Gao J, Wang B, Mao JF, et al (2012) Demography and speciation history of the homoploid hybrid pine Pinus densata on the Tibetan Plateau. Mol Ecol 21:48114827. https://doi.org/10.1111/j.1365-294X.2012.05712.x

Gernandt DS, Aguirre Dugua X, Vázquez-Lobo A, et al (2018) Multi-locus phylogenetics, lineage sorting, and reticulation in Pinus subsection Australes. Am J Bot 105:711-725. https://doi.org/10.1002/AJB2.1052

Goudet J, Jombart T (2020) hierfstat, estimations and tests of hierarchical F-statistics. R package version 0.5-7. https://CRAN.R-project.org/package=hierfstat

Gougherty A V., Chhatre VE, Keller SR, Fitzpatrick MC (2020) Contemporary range position predicts the range-wide pattern of genetic diversity in balsam poplar (Populus balsamifera L.). J Biogeogr 47:1246-1257. https://doi.org/10.1111/jbi.13811

Gugger PF, Ikegami M, Sork VL (2013) Influence of late Quaternary climate change on present patterns of genetic variation in valley oak, Quercus lobata Née. Mol Ecol 22:3598-3612. https://doi.org/10.1111/MEC.12317 
Divergence amid recurring gene flow

Gutenkunst RN, Hernandez RD, Williamson SH, Bustamante CD (2009) Inferring the joint demographic history of multiple populations from multidimensional SNP frequency data. PLoS Genet 5:1-11. https://doi.org/10.1371/journal.pgen.1000695

Hagman M (1975) Incompatibility in forest trees. Proc R Soc London Ser B Biol Sci 188:313-326.

Hamilton JA, De la Torre AR, Aitken SN (2015) Fine-scale environmental variation contributes to introgression in a three-species spruce hybrid complex. Tree Genet Genomes 11. https://doi.org/10.1007/s11295-014-0817-y

Hapke A, Thiele D (2016) GlbPSs: a toolkit for fast and accurate analyses of genotyping-by-sequencing data without a reference genome. Mol Ecol Resour 16:979-990. https://doi.org/10.1111/1755-0998.12510

Hernández-León S, Gernandt DS, Pérez de la Rosa J a., Jardón-Barbolla L (2013) Phylogenetic relationships and species delimitation in Pinus section Trifoliae inferrred from plastid DNA. PLoS One 8:1-14. https://doi.org/10.1371/journal.pone.0070501

Hernández-Serrano A, Verdú M, González-Martínez SC, Pausas JG (2013) Fire structures pine serotiny at different scales. Am J Bot 100:2349-2356. https://doi.org/10.3732/aib.1300182

Herten K, Hestand MS, Vermeesch JR, Van Houdt JKJ (2015) GBSX: A toolkit for experimental design and demultiplexing genotyping by sequencing experiments. BMC Bioinformatics 16:1-6. https://doi.org/10.1186/s12859-015-0514-3

Hewitt GM (2001) Speciation, hybrid zones and phylogeography - Or seeing genes in space and time. Mol Ecol 10:537-549. https://doi.org/10.1046/J.1365294X.2001.01202.X

Hewitt GM (2004) Genetic consequences of climatic oscillations in the Quaternary. Philos Trans R Soc Lond B 359:183-195. https://doi.org/10.1098/rstb.2003.1388

Hickerson MJ, Carstens BC, Cavender-Bares J, et al (2010) Phylogeography's past, present, and future: 10 years after. Mol Phylogenet Evol 54:291-301. https://doi.org/10.1016/J.YMPEV.2009.09.016

Hijmans RJ, Cameron SE, Parra JL, et al (2005) Very high resolution interpolated climate surfaces for global land areas. Int J Climatol 25:1965-1978. https://doi.org/10.1002/JOC.1276

Hijmans RJ (2019). geosphere: Spherical trigonometry. R package version 1.5-10. https://CRAN.R-project.org/package=geosphere 
Divergence amid recurring gene flow

894

895

896

897

898

899

900

901

902

903

904

905

906

907

908

909

910

911

912

913

914

915

916

917

918

919

920

921

922

923

924

925

926

927

928

929

930

931

Hohenlohe PA, Day MD, Amish SJ, et al (2013) Genomic patterns of introgression in rainbow and westslope cutthroat trout illuminated by overlapping paired-end RAD sequencing. Mol Ecol 22:3002-3013. https://doi.org/10.1111/mec.12239

Ikeda DH, Max TL, Allan GJ, et al (2017) Genetically informed ecological niche models improve climate change predictions. Glob Chang Biol 23:164-176. https://doi.org/10.1111/gcb.13470

Jetton RM, Crane BS, Whittier WA, Dvorak WS (2015) Genetic resource conservation of Table Mountain pine (Pinus pungens) in the central and southern Appalachian Mountains. Tree Plant Notes 58:42-52

Jin WT, Gernandt DS, Wehenkel C, et al (2021) Phylogenomic and ecological analyses reveal the spatiotemporal evolution of global pines. Proc Natl Acad Sci USA 118. https://doi.org/10.1073/PNAS.2022302118/-/DCSUPPLEMENTAL

Ju M-M, Feng L, Yang J, et al (2019) Evaluating population genetic structure and demographic history of Quercus spinosa (Fagaceae) based on specific length amplified fragment sequencing. Front Genet 10:965. https://doi.org/10.3389/FGENE.2019.00965

Jump AS, Peñuelas J (2005) Running to stand still: Adaptation and the response of plants to rapid climate change. Ecol Lett 8:1010-1020. https://doi.org/10.1111/i.1461-0248.2005.00796.x

Kass JM, Muscarella R, Galante PJ, et al (2021) ENMeval 2.0: Redesigned for customizable and reproducible modeling of species' niches and distributions. Methods Ecol Evol 12:1602-1608. https://doi.org/10.1111/2041-210X.13628

Keller SR, Olson MS, Salim S, et al (2010) Genomic diversity, population structure, and migration following rapid range expansion in the Balsam poplar, Populus balsamifera. Mol Ecol 19:1212-1226. https://doi.org/10.1111/i.1365294X.2010.04546.X

Keeley JE (2012) Ecology and evolution of pine life histories. Ann For Sci 69:445-453. https://doi.org/10.1007/s13595-012-0201-8

Kim BY, Wei X, Fitz-Gibbon S, et al (2018) RADseq data reveal ancient, but not pervasive, introgression between Californian tree and scrub oak species (Quercus sect. Quercus: Fagaceae). Mol Ecol 27:4556-4571. https://doi.org/10.1111/MEC.14869

Kriebel HB (1972). Embryo development and hybridity barriers in the white pines (Section Strobus). Silvae Genet 21:39-44. 
Divergence amid recurring gene flow

932 Kulmuni J, Butlin RK, Lucek K, et al (2020) Towards the completion of speciation: The

933

934

935

936

937

938

939

940

941

942

943

944

945

946

947

948

949

950

951

952

953

954

955

956

957

958

959

960

961

962

963

964

965

966

967

968

969

970

971

972

973 evolution of reproductive isolation beyond the first barriers: Progress towards complete speciation. Philos Trans R Soc B Biol Sci 375:20190528. https://doi.org/10.1098/rstb.2019.0528

Łabiszak B, Zaborowska J, Wójkiewicz B, Wachowiak W (2021) Molecular and paleoclimatic data uncover the impact of an ancient bottleneck on the demographic history and contemporary genetic structure of endangered Pinus uliginosa. J Syst Evol 59:596-610. https://doi.org/10.1111/ise.12573

Lafontaine G de, Prunier J, Gérardi S, Bousquet J (2015) Tracking the progression of speciation: variable patterns of introgression across the genome provide insights on the species delimitation between progenitor-derivative spruces (Picea mariana $\times$. rubens). Mol Ecol 24:5229-5247. https://doi.org/10.1111/MEC.13377

Lascoux M, Palmé AE, Cheddadi R, Latta RG (2004) Impact of Ice Ages on the genetic structure of trees and shrubs. Philos Trans R Soc Lond B Biol Sci 359:197-207. https://doi.org/10.1098/rstb.2003.1390

Ledig FT, Smouse PE, Hom JL (2015) Postglacial migration and adaptation for dispersal in pitch pine (Pinaceae). Am J Bot 102:2074-2091. https://doi.org/10.3732/AJB.1500009

Legendre P, Legendre L (2012) Numerical Ecology. Third Edition. Elsevier.

Li L, Abbott RJ, Liu B, et al (2013) Pliocene intraspecific divergence and PlioPleistocene range expansions within Picea likiangensis (Lijiang spruce), a dominant forest tree of the Qinghai-Tibet Plateau. Mol Ecol 22:5237-5255. https://doi.org/10.1111/MEC.12466

Lima JS, Telles MPC, Chaves LJ, et al (2017) Demographic stability and high historical connectivity explain the diversity of a savanna tree species in the Quaternary. Ann Bot 119:645-657. https://doi.org/10.1093/AOB/MCW257

Lind BM, Menon M, Bolte CE, et al (2018) The genomics of local adaptation in trees: are we out of the woods yet? Tree Genet Genomes 14:29. https://doi.org/10.1007/s11295-017-1224-y

Little EL Jr. (1971) Atlas of United States trees, Vol. 1, conifers and important hardwoods: U.S. Department of Agriculture, 1146, 9, p200

Mantel N (1967) The detection of disease clustering and a generalized regression approach. Cancer Research 27: 209-220.

McKinney GJ, Waples RK, Seeb LW, Seeb JE (2017) Paralogs are revealed by proportion of heterozygotes and deviations in read ratios in genotyping-by- 
Divergence amid recurring gene flow

974

975

976

977

978

979

980

981

982

983

984

985

986

987

988

989

990

991

992

993

994

995

996

997

998

999

1000

1001

1002

1003

1004

1005

1006

1007

1008

sequencing data from natural populations. Mol Ecol Resour 17:656-669. https://doi.org/10.1111/1755-0998.12613

McKinney GJ, Waples RK, Pascal CE, et al (2018) Resolving allele dosage in duplicated loci using genotyping-by-sequencing data: A path forward for population genetic analysis. Mol Ecol Resour 18:570-579. https://doi.org/10.1111/1755$\underline{0998.12763}$

McWilliam JR (1959) Interspecific Incompatibility in Pinus. Am J Bot 46:425-433

Menon M, Bagley JC, Friedline CJ, et al (2018) The role of hybridization during ecological divergence of southwestern white pine (Pinus strobiformis) and limber pine (P. flexilis). Mol Ecol 27:1245-1260. https://doi.org/10.1111/MEC.14505

Michaux, FA (1819) The North American Sylva, or A description of the forest trees of the United States, Canada and Nova Scotia considered particularly with respect to their use in the arts, and their introduction into commerce; to which is added a description of the most useful of the European forest trees: illustrated by 156 coloured engravings. C. d'Hautel, Paris https://doi.org/10.5962/bhl.title.48807

Nosil, P (2012) Ecological Speciation. Oxford: Oxford University Press. https://doi.org/10.1093/acprof:osobl/9780199587100.001.0001

Nosil P, Feder JL (2012) Widespread yet heterogeneous genomic divergence. Mol Ecol $21: 2829-2832$. https://doi.org/10.1111/j.1365-294X.2012.05580.x

Oksanen J, Blanchet FG, Friendly M, et al (2020) vegan: Community ecology package. $R$ package version 2.5-7. https://CRAN.R-project.org/package=vegan

Otto-Bliesner BL, Marshall SJ, Overpeck JT, et al (2006) Simulating Arctic climate warmth and icefield retreat in the last interglaciation. Sci 311:1751-1753. https://doi.org/10.1126/science. 1120808

Parchman TL, Gompert Z, Mudge J, et al (2012) Genome-wide association genetics of an adaptive trait in lodgepole pine. Mol Ecol 21:2991-3005. https://doi.org/10.1111/j.1365-294X.2012.05513.x

Parchman TL, Jahner JP, Uckele KA, et al (2018) RADseq approaches and applications for forest tree genetics. Tree Genet. Genomes 14. https://doi.org/10.1007/s11295$\underline{018-1251-3}$

Parisien MA, Moritz MA (2009) Environmental controls on the distribution of wildfire at multiple spatial scales. Ecol Monogr 79:127-154. https://doi.org/10.1890/07-1289.1 
Divergence amid recurring gene flow

1009

1010

1011

1012

1013

1014

1015

1016

1017

1018

1019

1020

1021

1022

1023

1024

1025

1026

1027

1028

1029

1030

1031

1032

1033

1034

1035

1036

1037

1038

1039

1040

1041

1042

1043

1044

1045

1046

Park B, Donoghue MJ (2019) Phylogeography of a widespread eastern North American shrub, Viburnum lantanoides. Am J Bot 106:389-401. https://doi.org/10.1002/AJB2.1248

Pausas JG, Schwilk D (2012) Fire and plant evolution. New Phytol 193:301-303. https://doi.org/10.1111/j.1469-8137.2011.04010.x

Perron M, Perry DJ, Andalo C, Bousquet J (2000) Evidence from sequence-tagged-site markers of a recent progenitor-derivative species pair in conifers. Proc Natl Acad Sci USA 97:11331-11336. https://doi.org/10.1073/PNAS.200417097

Peterson BK, Weber JN, Kay EH, et al (2012) Double digest RADseq: An inexpensive method for de novo SNP discovery and genotyping in model and non-model species. PLoS One 7:e37135 . https://doi.org/10.1371/journal.pone.0037135

Peterson AT, Anamza T (2015) Ecological niches and present and historical geographic distributions of species: A 15-year review of frameworks, results, pitfalls, and promises. Folia Zool 64:207-217. https://doi.org/10.25225/FOZO.V64.I3.A3.2015

Petit RJ, Hampe A (2006) Some evolutionary consequences of being a tree. Annu Rev Ecol Evol Syst 37:187-214. https://doi.org/10.1146/annurev.ecolsys.37.091305.110215

Phillips SJ, Anderson RP, Dudík M, et al (2017) Opening the black box: an open-source release of Maxent. Ecography 40:887-893. https://doi.org/10.1111/ECOG.03049

Puritz JB, Hollenbeck CM, Gold JR (2014) dDocent: A RADseq, variant-calling pipeline designed for population genomics of non-model organisms. PeerJ 2:e431. https://doi.org/10.7717/peeri.431

R Core Team (2021) R: A Language and environment for statistical computing. $R$ Foundation for Statistical Computing, Vienna, Austria. URL https://www.Rproject.org/

Raj A, Stephens M, Pritchard JK (2014) FastSTRUCTURE: Variational inference of population structure in large SNP data sets. Genetics 197:573-589. https://doi.org/10.1534/genetics.114.164350

Richards CL, Carstens BC, Lacey Knowles L (2007) Distribution modelling and statistical phylogeography: An integrative framework for generating and testing alternative biogeographical hypotheses. J. Biogeogr. 34:1833-1845. https://doi.org/10.1111/j.1365-2699.2007.01814.x

Saladin B, Leslie AB, Wüest RO, et al (2017) Fossils matter: improved estimates of divergence times in Pinus reveal older diversification. BMC Evol Biol 17:95. https://doi.org/10.1186/S12862-017-0941-Z 
Divergence amid recurring gene flow

1047

1048

1049

1050

1051

1052

1053

1054

1055

1056

1057

1058

1059

1060

1061

1062

1063

1064

1065

1066

1067

1068

1069

1070

1071

1072

1073

1074

1075

1076

1077

1078

1079

1080

1081

Savolainen O, Bokma F, García-Gil R, et al (2004) Genetic variation in cessation of growth and frost hardiness and consequences for adaptation of Pinus sylvestris to climatic changes. For Ecol Manage 197:79-89.

https://doi.org/10.1016/i.foreco.2004.05.006

Seehausen O, Butlin RK, Keller I, et al (2014) Genomics and the origin of species. Nat Rev Genet 15:176-192. https://doi.org/10.1038/nrg3644

Soltis DE, Morris AB, McLachlan JS, et al (2006) Comparative phylogeography of unglaciated eastern North America. Mol Ecol 15:4261-4293. https://doi.org/10.1111/i.1365-294X.2006.03061.x

Sousa VC, Grelaud A, Hey J (2011) On the nonidentifiability of migration time estimates in isolation with migration models. Mol Ecol 20:3956-3962. https://doi.org/10.1111/i.1365-294X.2011.05247.x

Stetter MG, Thornton K, Ross-Ibarra J (2018) Genetic architecture and selective sweeps after polygenic adaptation to distant trait optima. PLoS Genet 14:e1007794. https://doi.org/10.1101/313247

Svenning JC, Eiserhardt WL, Normand S, et al (2015) The Influence of Paleoclimate on Present-Day Patterns in Biodiversity and Ecosystems. Annu Rev Ecol Evol Syst 46:551-572. https://doi.org/10.1146/annurev-ecolsys-112414-054314

Vallejo-Marín M, Hiscock SJ (2016) Hybridization and hybrid speciation under global change. New Phytol 211:1170-1187. https://doi.org/10.1111/nph.14004

Vasilyeva G, Goroshkevich S (2018) Artificial crosses and hybridization frequency in five-needle pines. Dendrobiology 80:123-130. https://doi.org/10.12657/denbio.080.012

Wang IJ, Bradburd GS (2014) Isolation by environment. Mol Ecol 23:5649-5662. https://doi.org/10.1111/mec.12938

Warren DL, Glor RE, Turelli M (2008) Environmental niche equivalency versus conservatism: Quantitative approaches to niche evolution. Evolution 62:2868-2883. https://doi.org/10.1111/J.1558-5646.2008.00482.X

Warren DL, Matzke NJ, Cardillo M, et al (2021) ENMTools 1.0: an R package for comparative ecological biogeography. Ecography 44:504-511. https://doi.org/10.1111/ecog.05485

Welch NT, Waldrop TA (2001) Restoring Table Mountain pine (Pinus pungens Lamb.) communities with prescribed fire: An overview of current research. Castanea $66: 42-49$. 
Divergence amid recurring gene flow

1082 Williams JW, Jackson ST (2007) Novel climates, no-analog communities, and

1083 ecological surprises. Front Ecol Environ 5:475-482. https://doi.org/10.1890/070037

1084 Wright S (1943) Isolation by distance. Genetics 28:114-138.

1085 Wright JW (1959) Species hybridization in the white pines. Forest Sci 5:210-222.

1086 Yang R-C (1998) Estimating hierarchical F-statistics. Evolution 52:950-956.

1087 https://doi.org/10.2307/2411227

1088 Yang YX, Zhi LQ, Jia Y, et al (2020) Nucleotide diversity and demographic history of Pinus bungeana, an endangered conifer species endemic in China. J Syst Evol

1091 58:282-294. https://doi.org/10.1111/jse.12546

1094 Zou J, Sun Y, Li L, et al (2013) Population genetic evidence for speciation pattern and 1095 gene flow between Picea wilsonii, P. morrisonicola and $P$. neoveitchii. Ann Bot 1096 112:1829-1844. https://doi.org/10.1093/AOB/MCT241

1097

1098

1099

1100

1101

1102 
Divergence amid recurring gene flow

a)

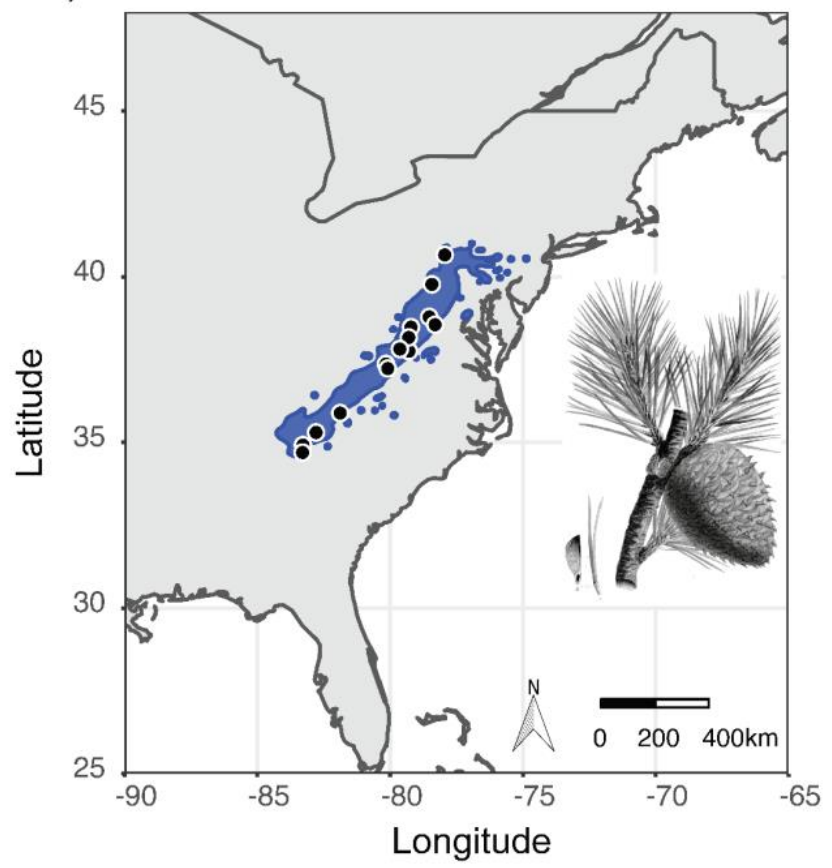

b)

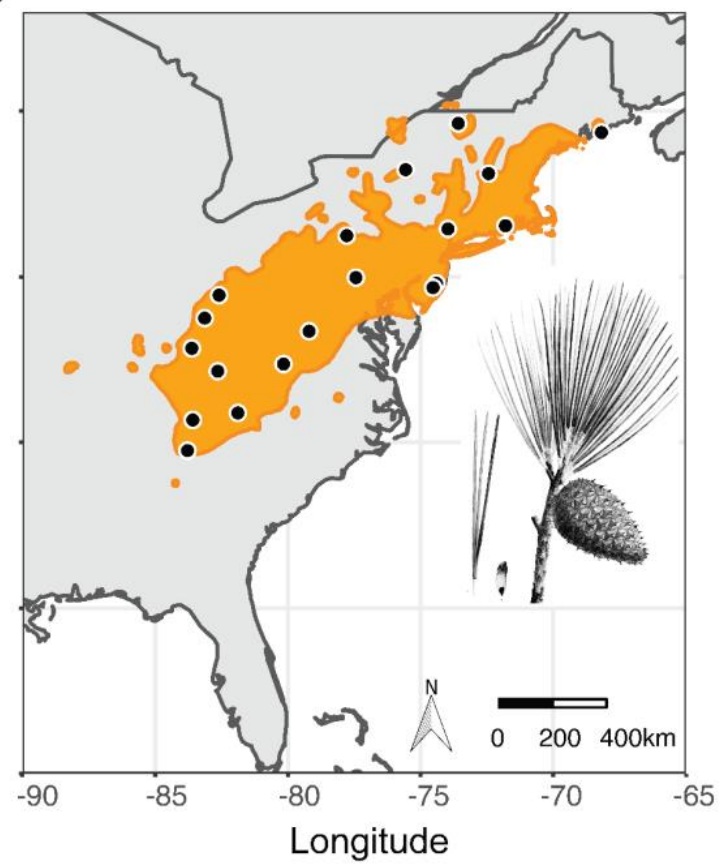

Fig. 1 Known geographical distribution of focal species, a) Pinus pungens and b) $P$. rigida, (Little 1971) in relation to populations sampled (black dots) for genetic analysis; Phenotypic characterization of each species was illustrated by Pierre-Joseph Redouté (Michaux 1819) 


\section{Divergence amid recurring gene flow}

1129 Table 1 Location of sampled populations, number of trees $(n)$ that were sampled, and the 1130 observed heterozygosity $\left(H_{0}\right)$ versus the expected heterozygosity $\left(H_{\mathrm{e}}=2 p q\right)$ for Pinus 1131 pungens and $P$. rigida populations.

1132

\begin{tabular}{|c|c|c|c|c|c|c|c|}
\hline Species & Code & Location & Lat & Long & $n$ & $H_{0}$ & $H_{\mathrm{e}}$ \\
\hline P. pungens & PU_BB & Briery Branch, VA & 38.48 & -79.22 & 8 & 0.110 & 0.108 \\
\hline P. pungens & PU_BN & Buchanan State Forest, PA & 39.77 & -78.43 & 6 & 0.141 & 0.121 \\
\hline P. pungens & PU_BV & Buena Vista, VA & 37.76 & -79.29 & 11 & 0.124 & 0.120 \\
\hline P. pungens & PU_DT & Dragon's Tooth, VA & 37.37 & -80.16 & 7 & 0.101 & 0.098 \\
\hline P. pungens & PU_EG & Edinburg Gap, VA & 38.79 & -78.53 & 8 & 0.139 & 0.124 \\
\hline P. pungens & PU_EK & Elliott Knob, VA & 38.17 & -79.30 & 10 & 0.131 & 0.123 \\
\hline P. pungens & PU_GA & Walnut Fork, GA & 34.92 & -83.28 & 10 & 0.129 & 0.123 \\
\hline P. pungens & PU_LG & Looking Glass Rock, NC & 35.30 & -82.79 & 8 & 0.130 & 0.119 \\
\hline P. pungens & PU_NM & North Mountain, VA & 37.82 & -79.63 & 12 & 0.130 & 0.121 \\
\hline P. pungens & PU_PM & Poor Mountain, VA & 37.23 & -80.09 & 11 & 0.130 & 0.125 \\
\hline P. pungens & PU_SC & Pine Mountain, VA & 34.70 & -83.30 & 8 & 0.128 & 0.122 \\
\hline P. pungens & PU_SH & Shenandoah NP, VA & 38.55 & -78.31 & 5 & 0.160 & 0.128 \\
\hline P. pungens & PU_SV & Stone Valley Forest, PA & 40.66 & -77.95 & 9 & 0.110 & 0.110 \\
\hline P. pungens & PU_TR & Table Rock Mountain, NC & 35.89 & -81.88 & 12 & 0.113 & 0.114 \\
\hline P. rigida & RI_BR & Bass River State Forest, NJ & 39.80 & -74.41 & 9 & 0.101 & 0.105 \\
\hline P. rigida & RI_CT & Pachaug State Forest, CT & 41.54 & -71.81 & 10 & 0.096 & 0.107 \\
\hline$P$. rigida & RI_DT & Dragon's Tooth, VA & 37.37 & -80.16 & 10 & 0.109 & 0.106 \\
\hline P. rigida & RI_GA & Chattahoochee NF, GA & 34.75 & -83.78 & 9 & 0.096 & 0.103 \\
\hline P. rigida & RI_GW & George Washington NF, VA & 38.36 & -79.20 & 10 & 0.102 & 0.103 \\
\hline$P$. rigida & RI_HH & Hudson Highlands State Park, NY & 41.44 & -73.97 & 7 & 0.102 & 0.101 \\
\hline$P$. rigida & RI_JF & Jefferson NF, VA & 37.15 & -82.64 & 10 & 0.095 & 0.100 \\
\hline$P$. rigida & RI_KY & Daniel Boone NF, KY & 37.84 & -83.62 & 9 & 0.113 & 0.110 \\
\hline P. rigida & RI_ME & Acadia NP, ME & 44.36 & -68.19 & 10 & 0.107 & 0.106 \\
\hline P. rigida & RI_MI & Michaux State Forest, PA & 39.98 & -77.44 & 10 & 0.123 & 0.114 \\
\hline P. rigida & RI_NJ & Wharton State Forest, NJ & 39.68 & -74.53 & 9 & 0.098 & 0.101 \\
\hline P. rigida & RI_NY & Macomb State Park, NY & 44.63 & -73.58 & 9 & 0.101 & 0.104 \\
\hline P. rigida & RI_OH & South Bloomingville, $\mathrm{OH}$ & 39.45 & -82.59 & 8 & 0.093 & 0.096 \\
\hline P. rigida & RI_RS & Rome Sand Plains, NY & 43.23 & -75.56 & 9 & 0.097 & 0.103 \\
\hline P. rigida & RI_SH & Shawnee State Park, OH & 38.75 & -83.13 & 9 & 0.082 & 0.094 \\
\hline P. rigida & RI_SP & Sproul State Forest, PA & 41.24 & -77.78 & 9 & 0.106 & 0.105 \\
\hline P. rigida & RI_TN & Great Smoky Mountains NP, TN & 35.68 & -83.58 & 8 & 0.099 & 0.104 \\
\hline P. rigida & RI_TR & Table Rock Mountain, NC & 35.89 & -81.89 & 10 & 0.113 & 0.112 \\
\hline$P$. rigida & RI_VT & Bellows Falls, VT & 43.11 & -72.44 & 10 & 0.098 & 0.104 \\
\hline
\end{tabular}


Divergence amid recurring gene flow

a)

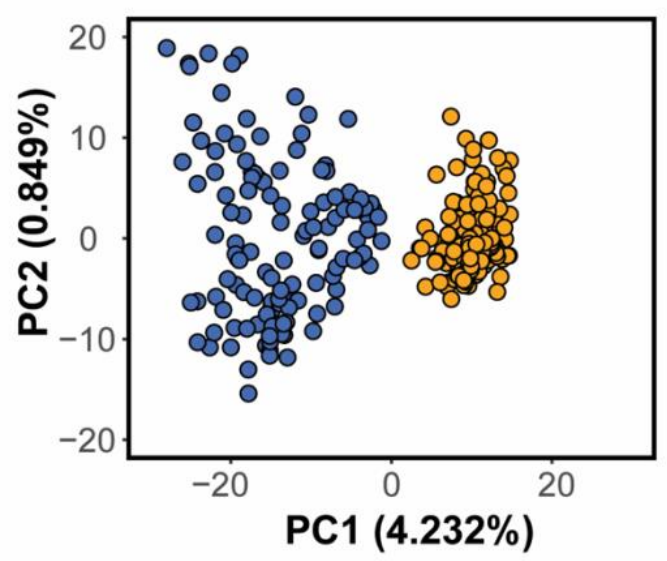

b)

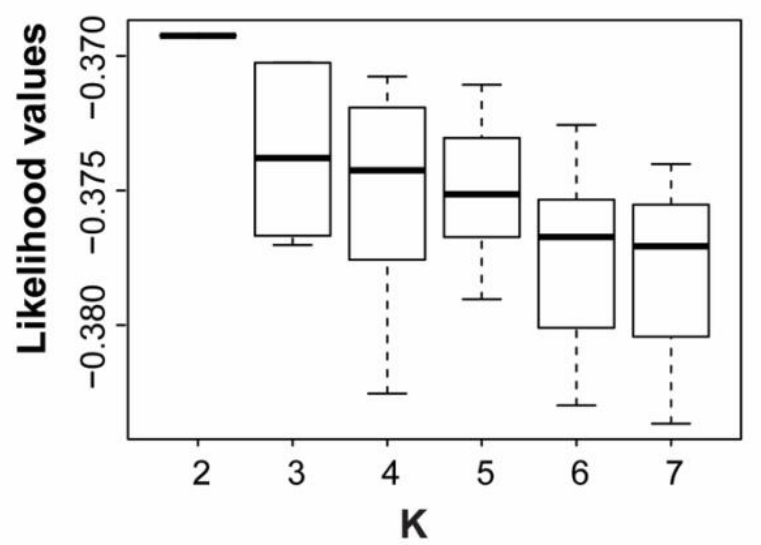

c)

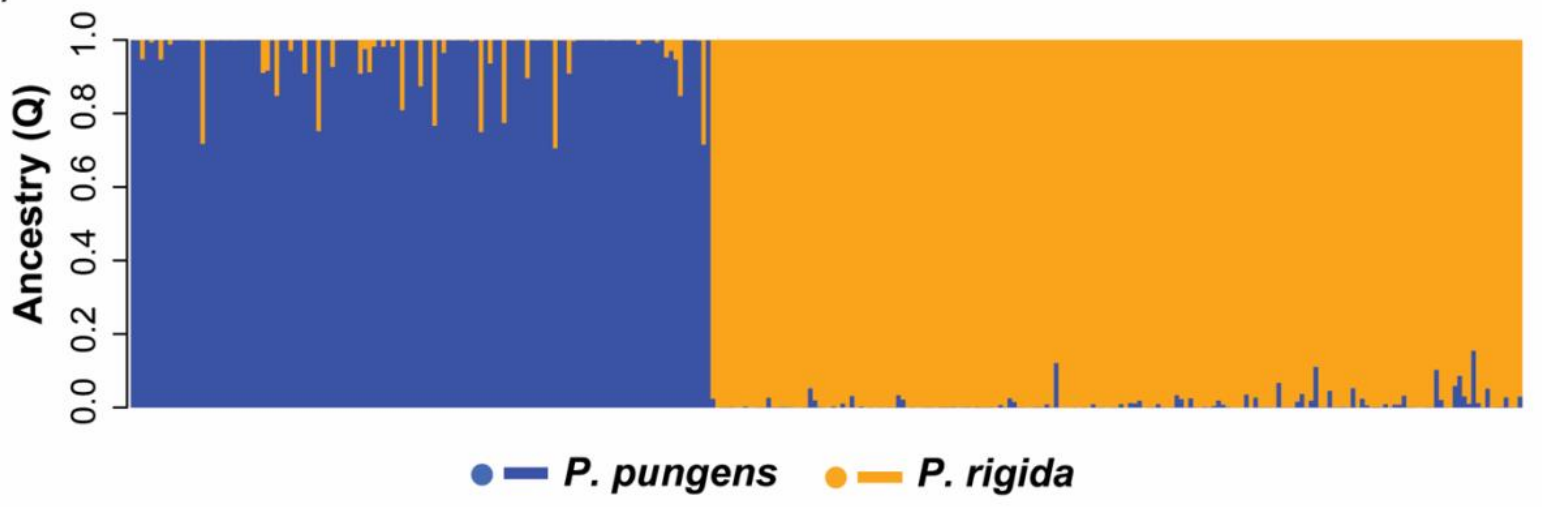

Fig. 2 Measures of genetic differentiation and diversity among sampled trees of $P$. pungens and $P$. rigida: a) Principal components analysis of 2168 genome-wide single nucleotide polymorphism (SNPs) for Pinus pungens (blue, left side of PC1) and $P$. rigida (orange, right side of $\mathrm{PC} 1$ ); b) log-likelihood values across ten replicate runs in fastSTRUCTURE for $K=2$ through $K=7$; c) results of averaged $K=2$ ancestry $(Q)$ assignments for each sample arranged latitudinally in each species 
Divergence amid recurring gene flow

1157 Table 2 Summary statistics of genetic differentiation for the sampled populations of $P$. 1158 rigida and $P$. pungens. Expected $\left(H_{\mathrm{e}}\right)$ and observed heterozygosity $\left(H_{0}\right)$ values are the 1159 averages across 2168 SNPs averaged across populations.

1160

\begin{tabular}{lccccc}
\hline Species & $\begin{array}{c}\boldsymbol{F S T}_{\mathrm{ST}} \\
\mathbf{( 9 5 \%} \mathrm{Cl})\end{array}$ & $\begin{array}{c}\text { IBD } \boldsymbol{r} \\
(\boldsymbol{p} \text {-value })\end{array}$ & $\begin{array}{c}\text { IBE } \boldsymbol{r} \\
(\boldsymbol{p} \text {-value })\end{array}$ & $\begin{array}{c}\boldsymbol{H}_{\mathrm{e}} \\
(\text { range })\end{array}$ & $\begin{array}{c}\boldsymbol{H}_{\mathrm{o}} \\
\text { (range) }\end{array}$ \\
\hline P. pungens & 0.0057 & -0.0789 & 0.0131 & 0.118 & 0.127 \\
& $(0.0032-0.0084)$ & $(0.638)$ & $(0.411)$ & $(0.098-0.129)$ & $(0.101-0.160)$ \\
P. rigida & 0.0056 & 0.1758 & -0.0669 & 0.104 & 0.102 \\
& $(0.0032-0.0082)$ & $(0.055)$ & $(0.633)$ & $(0.094-0.114)$ & $(0.082-0.123)$ \\
\hline
\end{tabular}

1161

1162

1163

1164

1165

1166

1167

1168

1169

1170

1171

1172

1173

1174

1175

1176

1177

1178 
Divergence amid recurring gene flow

1179

1180

1181

1182

1183

1184

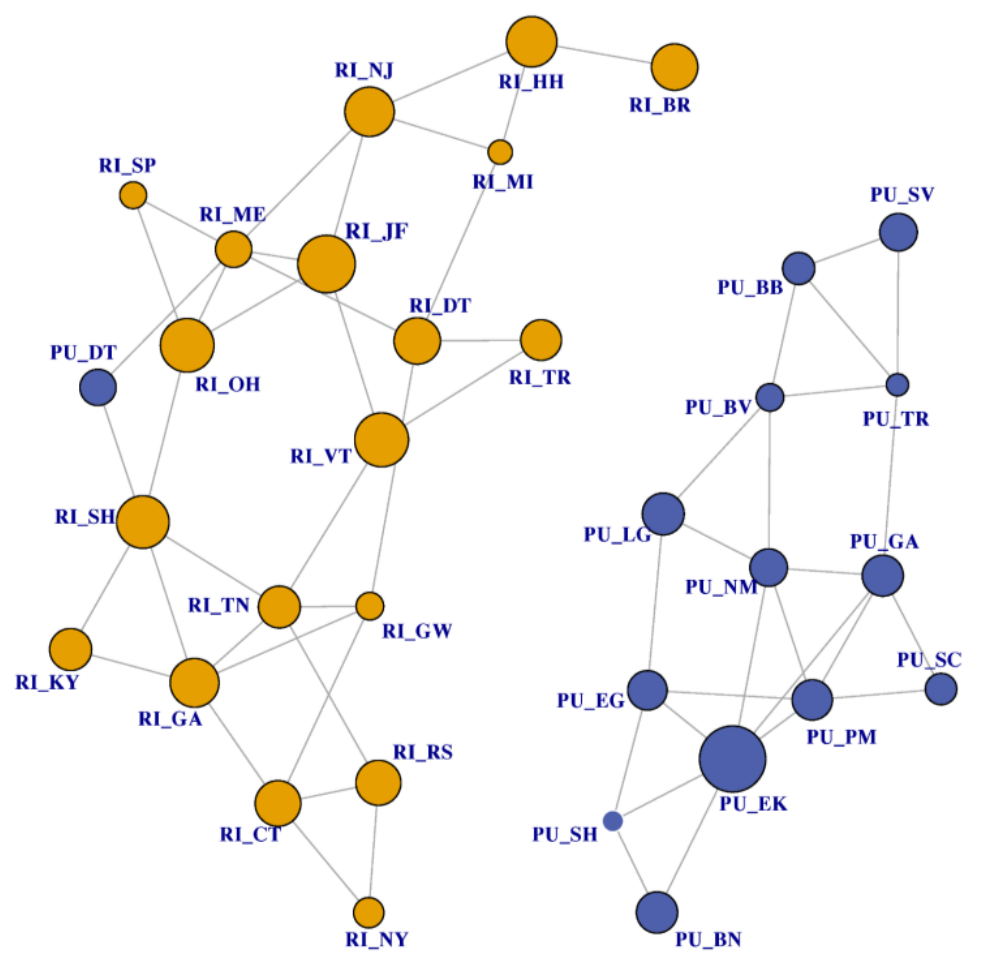

Fig. 3 Population graph reflecting the genetic relationships across all sampled populations of $P$. pungens (blue nodes, $\mathrm{PU} \_\mathrm{xx}$ labels) and $P$. rigida (orange nodes; $\mathrm{RI}$ _xx 
Divergence amid recurring gene flow

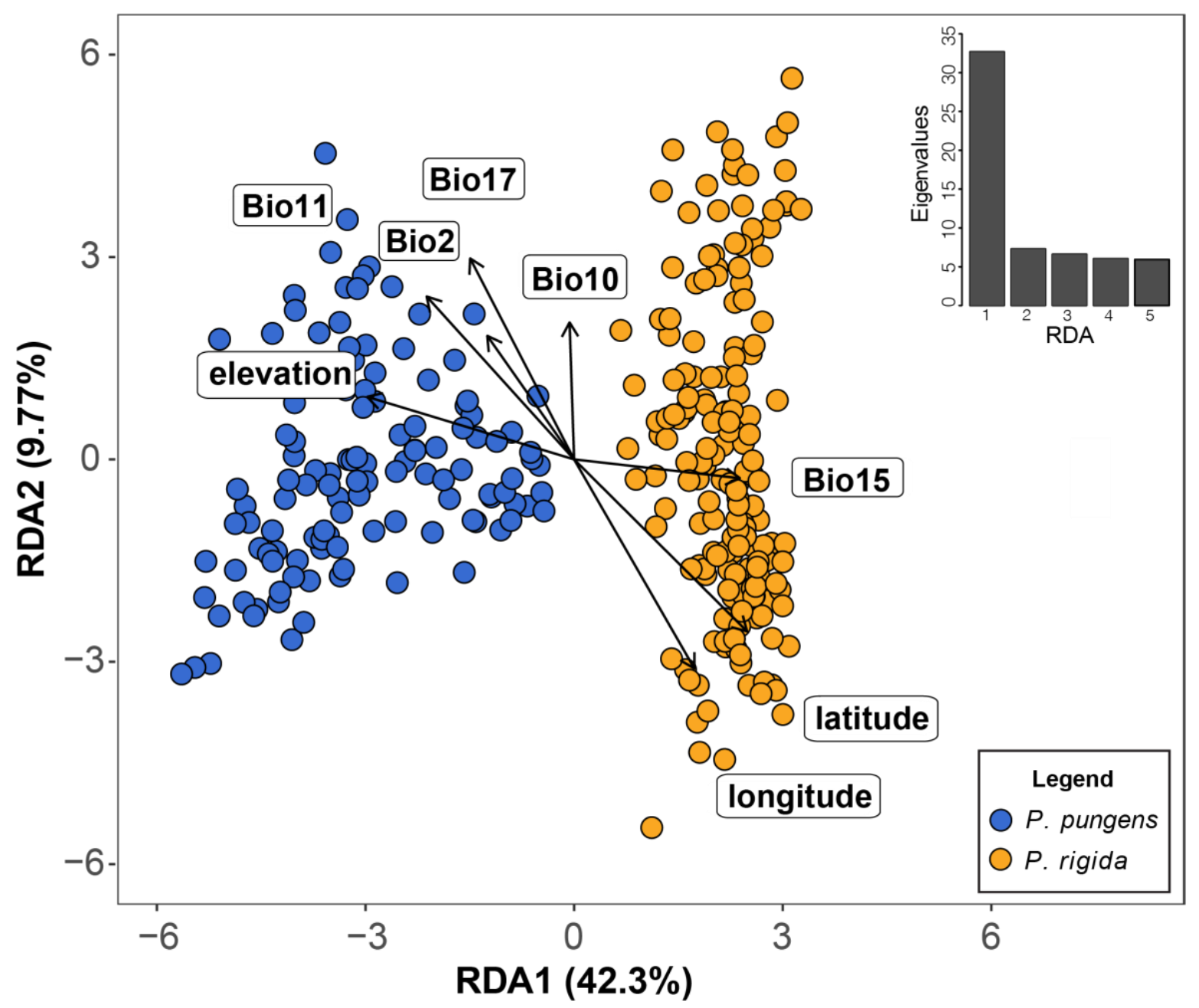

1185 1186 1187 1188

Fig. 4 Redundancy analysis (RDA) of the multilocus genotypes for each tree with climate and geographic predictor variables (full model). Direction and length of arrows on each RDA plot correspond to the loadings of each variable 
Divergence amid recurring gene flow
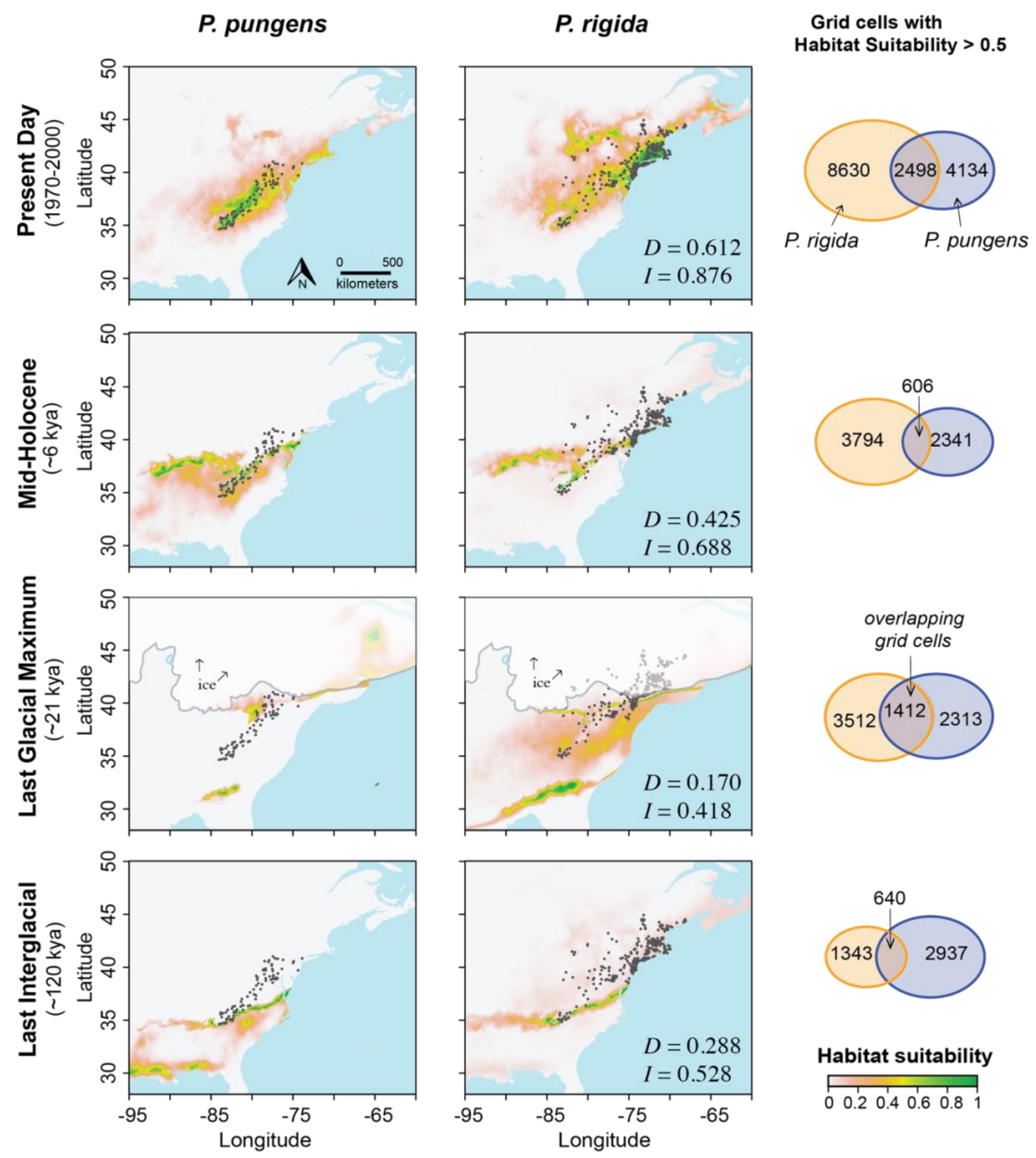

Habitat suitability

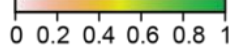

Fig. 5 Species distribution model (SDM) predictions across four time points for $P$. pungens and $P$. rigida. Measures of raster overlap in terms of Schoener's $D$ and Warren's I index between the models of each species, and at each time point, are presented in the bottom right corner of the prediction plots for $P$. rigida. Venn diagrams illustrate the number of grid cells with moderate to high habitat suitability scores $(>0.5)$ for each SDM at a given time point, as well as the number of shared, or overlapping, grid cells. Blue Venn diagram ovals show grid cell counts from the $P$. pungens SDM, and orange Venn diagram ovals show grid cell counts from the $P$. rigida SDM for the aligning time point (denoted on the left side). Glacial extent data (labeled ice in LGM plots) for 18 kya was provided by Dyke (2003) 
Divergence amid recurring gene flow

Table 3 Results of model fitting for twelve representative demographic models of divergence. Models are ranked by the number of parameters $(k)$. Log-likelihood $(\log L)$ and Akaike information criterion (AIC) are provided for each model. Model details are given in the footnote.

\begin{tabular}{llll}
\hline Model & $\boldsymbol{k}$ & $\log \boldsymbol{L}$ & AIC \\
\hline SI & 3 & -2254.18 & $4,514.37$ \\
MIGs & 4 & -2201.51 & $4,411.02$ \\
MIGa & 5 & -2210.81 & $4,431.62$ \\
SCs & 5 & -2213.93 & $4,437.86$ \\
SGFs & 5 & -2229.65 & $4,469.30$ \\
SCa & 6 & -2238.03 & $4,488.06$ \\
SGFa & 6 & -2241.07 & $4,494.14$ \\
PSC & 6 & -2277.78 & $4,567.56$ \\
PSCSCs & 7 & -2178.16 & $4,370.32$ \\
PSCMIGs & 7 & -1866.42 & $3,746.84$ \\
PSCMIGa & 8 & -2117.91 & $4,251.82$ \\
PSCMIGCs & 9 & -1853.99 & $3,726.00$ \\
\hline
\end{tabular}

$\mathrm{SI}$, strict isolation; MIGs, symmetrical gene flow; MIGa, asymmetrical gene flow; SCs, secondary contact with symmetrical gene flow; SCa, secondary contact with asymmetrical gene flow; SGFa, speciation with asymmetrical gene flow SGFs, speciation with symmetrical gene flow; PSC, population size change; MIGCs, change in rate of symmetrical gene flow. The best-fit model is in bold. 
Divergence amid recurring gene flow

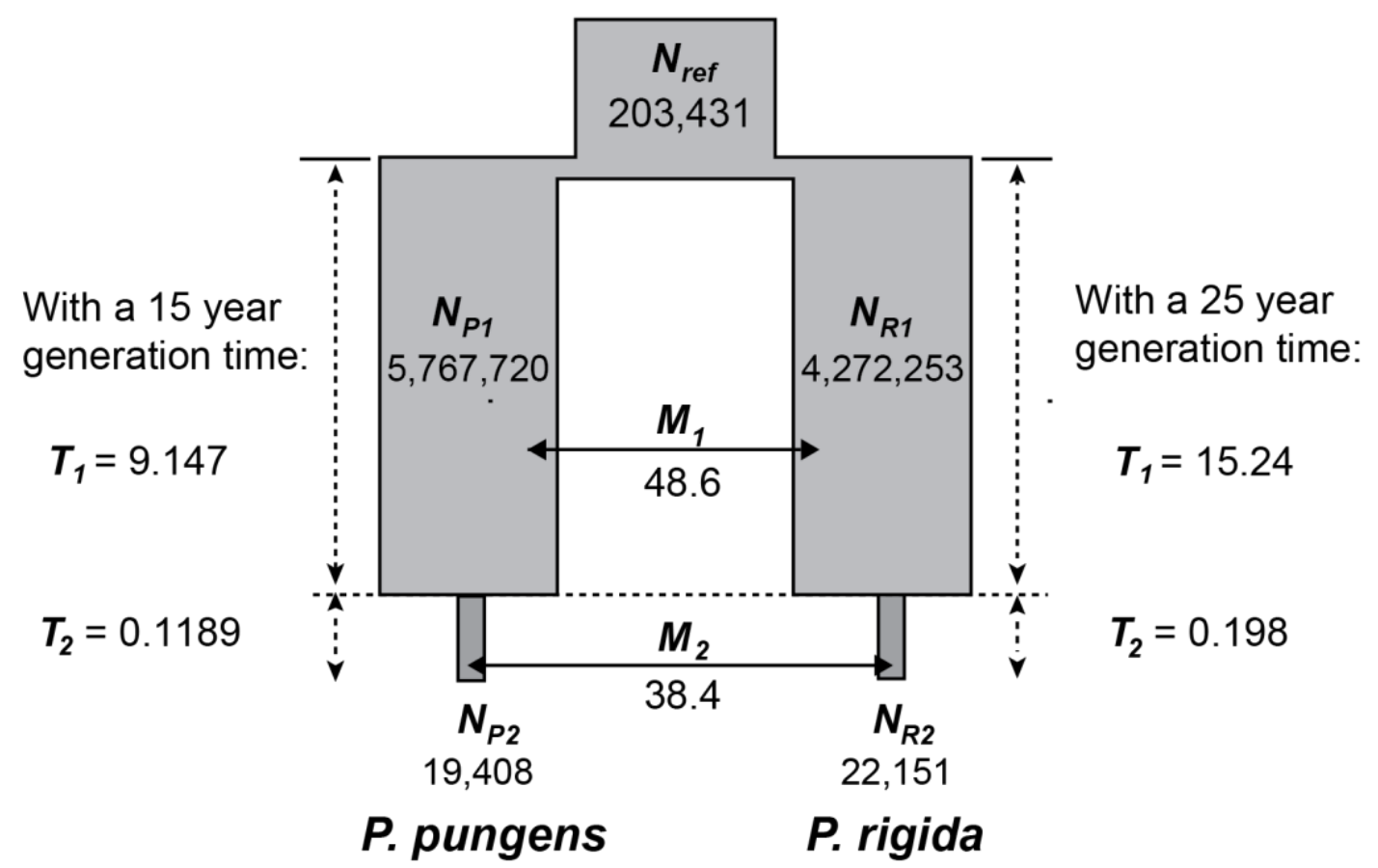

1216

1217

1218

1219

1220

1221

Fig. 6 The best-fit model (PSCMIGCs) and unscaled parameter estimates from $\partial \alpha \partial i$ analysis. Time intervals $\left(T_{i}\right)$ are represented in millions of years and associated with lineage population sizes $\left(N_{i}\right)$ and a specific rate of symmetrical gene flow $\left(M_{i}\right)$ 